BNL-113761-2017-IR

\title{
Atmospheric Tracer Depletion Testing for Unfiltered Air In-Leakage Determination at the Wolf Creek Nuclear Power Plant
}

\author{
T.M. Sullivan, R. J. Wilke, T. Roberts, and G. J. Vignato
}

Prepared for Wolf Creek Nuclear Operating Corporation

March 2017

Environmental \& Climate Sciences Dept.

\author{
Brookhaven National Laboratory
}

\section{U.S. Department of Energy USDOE Office of Science (SC), Biological and Environmental Research (BER) (SC-23)}

\footnotetext{
Notice: This manuscript has been authored by employees of Brookhaven Science Associates, LLC under Contract No. DE-SC0012704 with the U.S. Department of Energy. The publisher by accepting the manuscript for publication acknowledges that the United States Government retains a non-exclusive, paid-up, irrevocable, world-wide license to publish or reproduce the published form of this manuscript, or allow others to do so, for United States Government purposes.
} 


\section{DISCLAIMER}

This report was prepared as an account of work sponsored by an agency of the United States Government. Neither the United States Government nor any agency thereof, nor any of their employees, nor any of their contractors, subcontractors, or their employees, makes any warranty, express or implied, or assumes any legal liability or responsibility for the accuracy, completeness, or any third party's use or the results of such use of any information, apparatus, product, or process disclosed, or represents that its use would not infringe privately owned rights. Reference herein to any specific commercial product, process, or service by trade name, trademark, manufacturer, or otherwise, does not necessarily constitute or imply its endorsement, recommendation, or favoring by the United States Government or any agency thereof or its contractors or subcontractors. The views and opinions of authors expressed herein do not necessarily state or reflect those of the United States Government or any agency thereof.. 


\section{Brookhaven National Laboratory \\ Final Report}

\section{Atmospheric Tracer Depletion Testing for Unfiltered Air In-Leakage Determination at the Wolf Creek Nuclear Power Plant}

\section{T.M. Sullivan, R.J. Wilke, T. Roberts, and G.J. Vignato}

Prepared for

Wolf Creek Nuclear Operating Corporation

February, 2017

TTC - 0117, Rev. 0

Principal Preparer

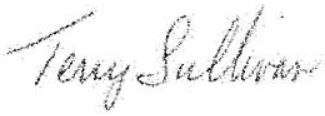

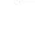

T

The sulivan,

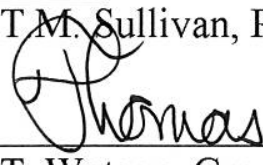

T. Watson, Group Leader

Technical Reviewer

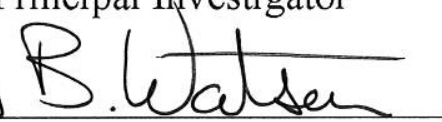

QA Reviewer

Final Approval

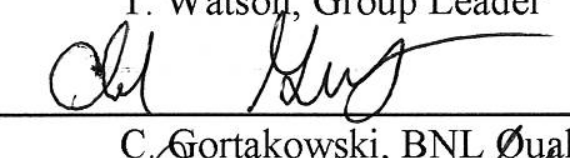

C. Gortakowski, BNL Øuality Office

P. Kalb, Deputy Department Chairman
Date_ $\quad \underline{3 / 31 / 17}$

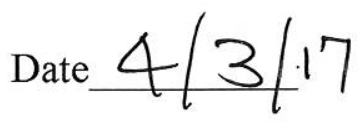

Date $4 / 3 / 2017$

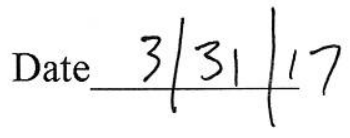

Tracer Technology Group

Environmental \& Climate Sciences Department

Brookhaven National Laboratory

Upton, New York 11973-5000 


\section{Atmospheric Tracer Depletion Testing for Unfiltered Air In-Leakage Determination at the Wolf Creek Nuclear Power Plant}

\section{Executive Summary}

Atmospheric Tracer Depletion tests were conducted at the Wolf Creek Nuclear Power Plant to quantify the unfiltered in-leakage (UI) into the Control Room (CR), Control Building (CB), and Equipment Rooms (ER) at the Wolf Creek Nuclear Power Plant. Wolf Creek has two independent charcoal filter Emergency Ventilation Systems (EVS) that can be used to purify air entering the control building and control room. The Bravo System contains a filtration system in Room 1501 in the Auxiliary Building for the Control Room and another filtration system (FGK02B) on Elevation 2016 for the Control Building. The Alpha system contains a filtration system in Room 1512 in the Auxiliary Building for the Control Room and another filtration system (FGK02A) on Elevation 2016 for the Control Building.

The Atmospheric Tracer Depletion (ATD) test is a technique to measure in-leakage using the concentration of perfluorocarbon compounds that have a constant atmospheric background. These levels are present in the Control Room and Control Building under normal operating conditions. When air is supplied by either of the EVS, most of the PFTS are removed by the charcoal filters. If the concentrations of the PFTs measured in protected areas are the same as the levels at the output of the EVS, the in-leakage of outside air into the protected area would be zero. If the concentration is higher in the protected area than at the output of the filter system, there is in-leakage and the inleakage can be quantified by the difference.

Sampling was performed using state-of-the-art Brookhaven Atmospheric Tracer Samplers (BATS) air sampling equipment and analysis performed on Brookhaven National Laboratory (BNL) dedicated PFT analytical systems. In the Alpha test two tracers PMCH and mcPDCH were used to determine in-leakage into the control building. The analytical system was tuned to maximize sensitivity after initial analysis of the Alpha test. The increased sensitivity permitted accurate quantification of five isomers of the PFT PDCH (mtPDCH, pcPDCH, otPDCH, mcPDCH, and ptPDCH). These isomers were quantified in the low concentration samples in the Alpha test and in all samples in the Bravo test.

The best estimates of $\mathrm{UI}\left(\mathrm{R}_{\mathrm{ui}}\right)$ for the four zones are provided in Table ES-1. For the CB, this estimate averages the four tracers at the four elevations. For the CR, this estimate uses the four sampling units located in the Control Room.

\section{Table ES-1 Best Estimate of Unfiltered In-Leakage Results}

\begin{tabular}{lllll} 
& Alpha Train & \multicolumn{3}{c}{ Bravo Train } \\
Location & $\mathrm{F}_{\text {dep }}$ & $\mathrm{R}_{\mathrm{ui}}(\mathrm{cfm})$ & $\mathrm{F}_{\text {dep }}$ & $\mathrm{R}_{\mathrm{ui}}(\mathrm{cfm})$ \\
\hline $\mathrm{CB}$ & 0.14 & $102 \pm 24$ & 0.121 & $88 \pm 4$ \\
$\mathrm{CR}$ & 0.0049 & $10 \pm 2$ & 0.0083 & $17 \pm 10$ \\
ER 1501 & 0.26 & 24 & 0.06 & $28 \pm 4$ \\
ER 1512 & 0.01 & $48 \pm 7$ & 0.08 & 3.3
\end{tabular}




\section{Table of Contents}

Executive Summary iv

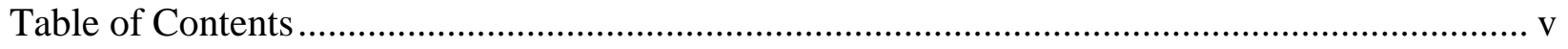

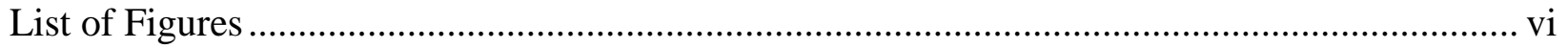

Wolf Creek Atmospheric Tracer Depletion In-Leakage Final Results..................................... 1

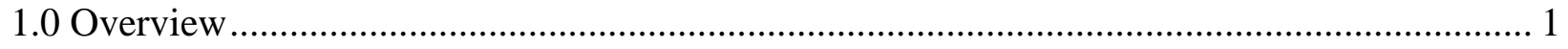

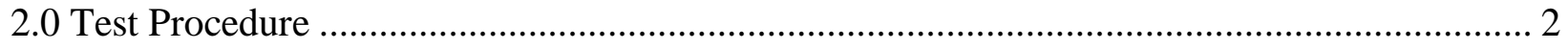

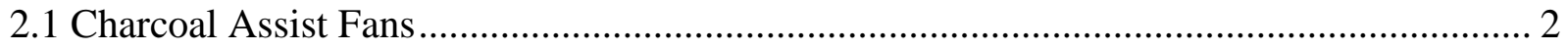

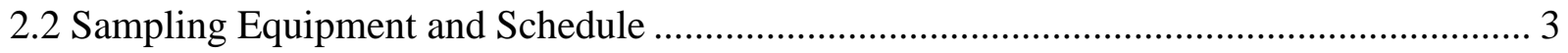

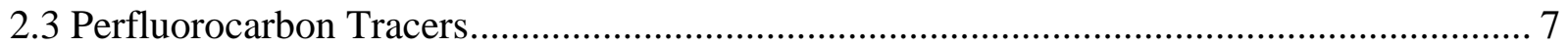

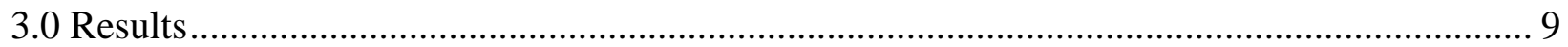

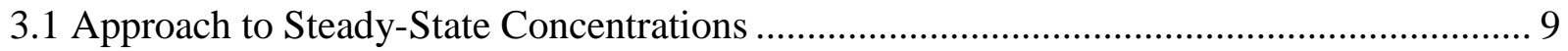

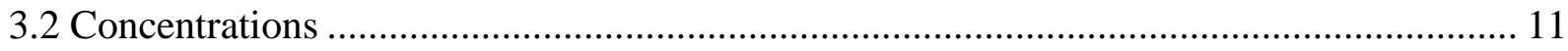

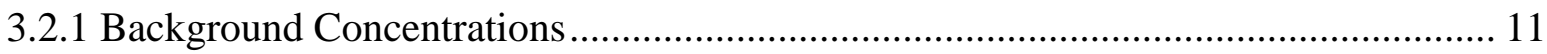

3.2.2 Control Building Concentrations ...................................................................... 12

3.2.3 Control Room (CR) Concentration Results ....................................................... 14

3.2.4 Equipment Room Concentrations .................................................................. 16

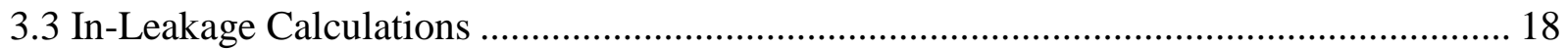

3.3.1 Control Building Unfiltered In-Leakage............................................................ 20

3.3.2 Control Room Unfiltered In-Leakage ................................................................. 23

3.3.3 Equipment Room Unfiltered In-Leakage.......................................................... 23

3.3.4 Summary of unfiltered in-leakage results ........................................................ 25

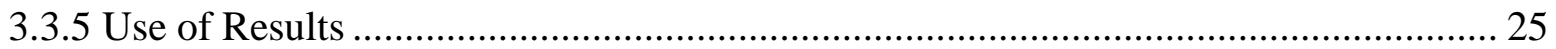

3.4 Comparison to 2004 and 2010 Test Results ........................................................... 26

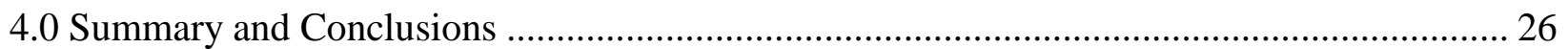

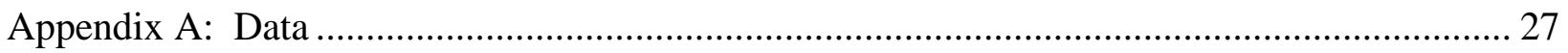

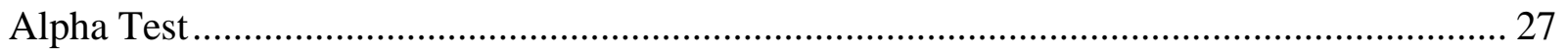

Control Building Elevation 2000 (Switchgear Rooms) ............................................. 27

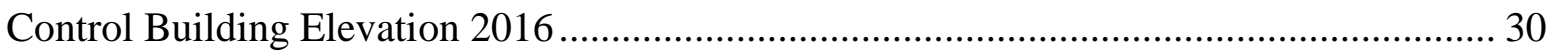

Control Building Elevation 2032 (Lower Cable Spreading Room)................................ 32

Control Building Elevation 2073 (Upper Cable Spreading Room) ................................ 34

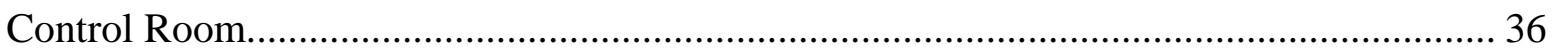

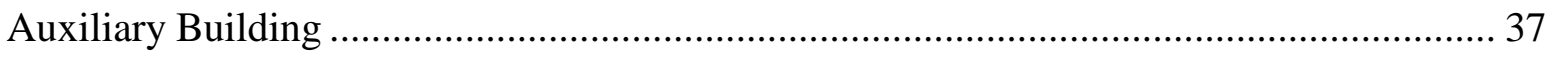

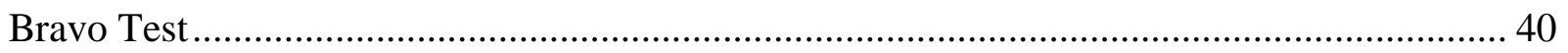

Control Building 2000-foot Elevation (Switchgear Rooms) ........................................ 40

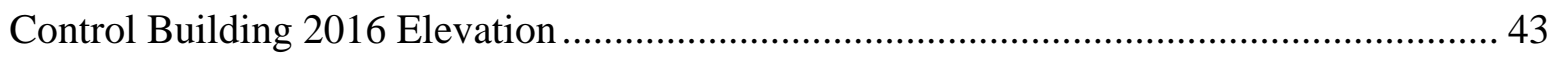


Control Building 2036-foot Elevation (Lower Cable Spreading Room) .............................. 46

Control Building Elevation 2073 (Upper Cable Spreading Room) ...................................... 48

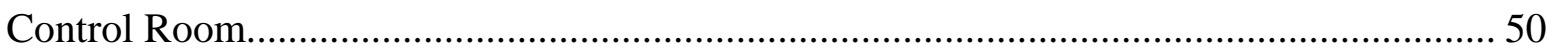

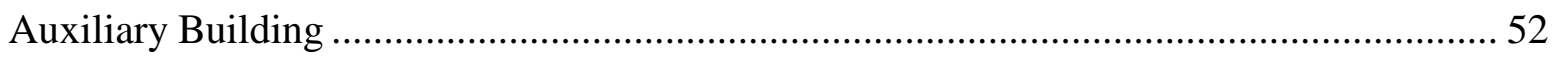

\section{List of Tables}

Table 1. Calculated Charcoal-Assist Run Times and Time to Steady State (SS) ......................... 2

Table 2 Sampling Systems and Sample Quantity*, Duration*, Rates, and Locations .................... 4

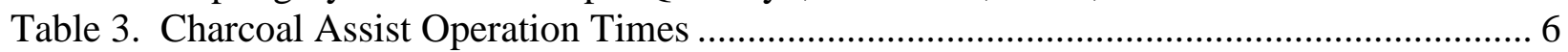

Table 4 Chemical Acronym, Name, and Formula for PFT Tracers.............................................. 7

Table 5 Background Concentrations (Area/L) in the Alpha Test................................................. 11

Table 6 Background concentrations (Area/L) measured during the Bravo tests.......................... 12

Table 7 CB Fractional depletion in the Alpha Test ………………......................................... 13

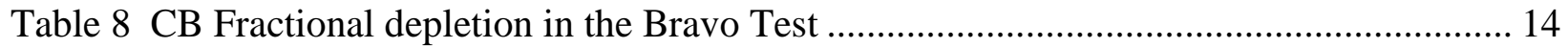

Table 9 Main Control Room $F_{\text {dep }}$ values at the end of the test................................................ 14

Table 10 Air concentrations after leaving the charcoal filter in the Auxiliary Building (BATS

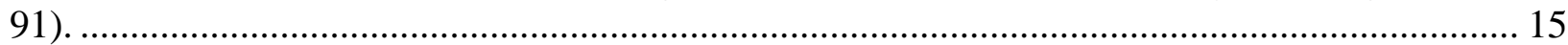

Table 11 Main Control Room $F_{\text {dep }}$ values at the end of the test adjusted for breakthrough ........ 16

Table 12 BATS F $F_{\text {dep }}$ values on the Auxiliary Room CREVS system .......................................... 17

Table 13 BATS $F_{\text {dep }}$ values for each tracer adjusted for breakthrough on the .............................. 17

Table 14 Equipment Room Concentrations Adjusted Fractional Depletion Values. ................... 18

Table 15 Nominal and measured flow rates of EVS systems................................................... 20

Table 16 Estimated Unfiltered In-leakage Rui (cfm) in the Control Building for the Alpha test.

Table 17 Estimated Unfiltered In-leakage Rui (cfm) in the Control Building for the Bravo test 22

Table 18 Estimated Unfiltered In-leakage (cfm) in the CR .................................................... 23

Table 19 Estimated unfiltered in-leakage in the active equipment room as a function of $\varepsilon 1 \ldots . . .24$

Table 20 Estimated unfiltered in-leakage in the inactive equipment room.................................. 24

Table 21 Summary of Unfiltered In-Leakage Results …………………………………….... 25

Table 22 Relative Exposure Levels ...................................................................................... 25

Table 23 Best estimate values for unfiltered in-leakage for Wolf Creek Control Room

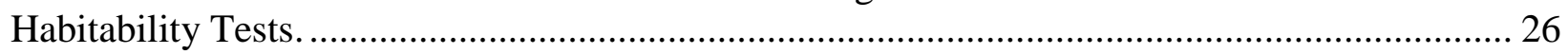

\section{List of Figures}

Figure 1 PMCH and mcPDCH concentrations at Location 3 2000-foot elevation SWGR 1-1... 10

Figure 2 PDCH isomers tracer concentrations at Location 3 2000-foot elevation ....................... 10

Figure 3 Outside air (background) concentrations for PMCH and mcPDCH. ............................. 11

Figure 4 Time-dependent mcPDCH concentration at Elevation 2032 ..................................... 13 


\section{Wolf Creek Atmospheric Tracer Depletion In-Leakage Final Results}

\subsection{Overview}

The Emergency Ventilation Systems used to protect the Control Room (CR), Control Building (CB), and Equipment Rooms (ER) At the Wolf Creek Nuclear power plant were were tested to quantify the unfiltered in-leakage (UI). Wolf Creek has two independent charcoal filter Emergency Ventilation Systems (EVS) that purify air entering the control building and control room, labeled Alpha and Bravo Both systems were tested.

The Atmospheric Tracer Depletion (ATD) is a technique that uses the atmospheric background of perfluorocarbon tracer (PFT) compounds and the removal of these compounds from the airstream filtered by the EVS systems to quantify UI. The PFTs will remain on the charcoal filter until heated above $200{ }^{\circ} \mathrm{C}$. The background level of the compounds is measured upstream of the filter system. The removal of the PFTs is measured at the output of the filter system, and the concentration of the PFTs are measured in the air of the protected zones. When the EVS system has been in operation for a time sufficient to reach steady-state, air samples collected in the zone can be used to identify and quantify UI. If there were no UI, the concentration throughout the protected zone would be the same as that at the output of the filter. If the concentration is higher, there is in-leakage and the in-leakage can be quantified.. Thus, any difference in concentration between the output of the filter system and points in the protected zone is a measure of in-leakage of unfiltered air.

For maximum accuracy in the assessment of in-leakage it is best if the EVS has run long enough to reach steady-state. For example, if the air sample was collected soon after the start of the EVS system, the measured concentrations would be close to background and the predicted in-leakage would be high. The longer the charcoal systems work, the lower the PFT concentrations, until steady-state is reached. Due to the large volumes of the CB $\left(365,000 \mathrm{ft}^{3}\right)$ and the flow rates of the CB EVS system $\left(750 \mathrm{ft}^{3} / \mathrm{min}\right)$, it would take several days for the charcoal filtration in the EVS to draw down the background levels of PFTs to their steady-state values. This is not practical for testing. To decrease the time to reach steady-state, additional charcoal filtration is needed. This is supplied using portable charcoal filter fan units that were acquired by Wolf Creek staff and were placed on the four levels of the Control Building (Elevation 2000 (Switchgear Room), El 2016 (Battery, CBEVS, and equipment rooms). El 2032 (Lower Cable Spreading Room), and El 2072 (Upper Cable Spreading Room) and in the active train Equipment Room in the Auxiliary Building. When the charcoal assist fans were operating, the double between the active and inactive equipment room were left open and fans were used to provide mixing between these two rooms. This is also the operating procedure for the doors on elevation 2016 and elevation 2000.

Brookhaven National Laboratory has a Quality Assurance Manual and operating procedures for Multi-tracer testing. These processes were reviewed by the Quality Assurance Office of Wolf Creek Nuclear Operating Corporation. Testing was performed in conformance the quality procedures. 


\subsection{Test Procedure}

The Wolf Creek Power Plant Control Building consists of rooms on four elevations that receive conditioned air from the Emergency Ventilation System (EVS). Elevation 2000 contains two Switchgear Rooms. Elevation 2016 contains two rooms containing the EVS equipment and several rooms containing switchgear, and other associated equipment. Elevation 2032 contains one large room, the Lower Cable Spreading Room. Elevation 2073 also contains one large room, the Upper Cable Spreading Room. The EVS system in the Control building filters approximately $750 \mathrm{cfm}$ of air. There are two independent EVS systems, Alpha and Bravo, for the Control Building.

The Control Room (CR), located at the 2047 Elevation has an EVS system rated at $2000 \mathrm{cfm}$. The CR EVS equipment is in the Auxiliary Building at the 2047 Elevation. There are two independent systems, Alpha and Bravo, for the Control Room. Equipment for the Alpha train is in Room 1512 and for the Bravo train in 1501. Ducting from the air handling equipment in these two rooms enters the CR and supplies filtered air that is recirculated through the EVS system.

Testing was conducted for both the Alpha and Bravo systems.

\subsection{Charcoal Assist Fans}

The calculations to measure in-leakage assume that steady-state has been reached. The initial conditions in the $\mathrm{CR}$ and $\mathrm{CB}$ are background concentrations of the PFTs. As the charcoal filters from the EVS are used, the ambient PFTs are removed and their levels decrease. At some point in time, the filtration is balanced with the in-leakage and a steady-state concentration is achieved within the test volume. The volume of the $\mathrm{CB}$ and the relatively small amount of filtered air $(750 \mathrm{cfm})$ would require a long time to reach steady-state. To accelerate this process four charcoal filter fan units are placed in the CB. The fans on the 2000 and 2016-foot elevation were rated at $1000 \mathrm{cfm}$. The fans on the 2032 and 2073 elevation were rated at $350 \mathrm{cfm}$. A 500-cfm fan was used in the Equipment Room (ER) to assist the CR in reaching steady-state faster. The time to draw the system down to steady-state was calculated for both trains based on the additional charcoal assist fans, their flow rates, building volumes and the 2010 measured in-leakage rates. The results are provided in Table 1 assumed $1000 \mathrm{cfm}$ fans on all levels of the CB.

Table 1. Calculated Charcoal-Assist Run Times and Time to Steady State (SS)

\begin{tabular}{lllll} 
& & Assumed & \multicolumn{2}{c}{ Run Times, hr. } \\
\cline { 4 - 5 } Location & Train & UI, cfm & CB & ER \\
\hline CB & A & 100 & 5.1 & 3.7 \\
" & B & 120 & 5.6 & $"$ \\
& Either & 30 & 3.5 &
\end{tabular}

Charcoal-Assist fans were utilized in each of the identified spaces though volumetric capacities varied from the estimate in some cases. The fans and run duration utilized resulted in achieving steady state 
for the test. Further detail regarding the accomplishment of steady state conditions is provided in section 3.1 of this report.

\subsection{Sampling Equipment and Schedule}

Based on previous tests, sampled air was expected to have fractional depletions running from 1.0 (outside air into the CBEVS - thus, no depletion), to: $\sim 0.1$ (CB SS levels): $<0.001$ (EVS filtered discharge air). Based on the 2010 results and pretest predictions, collecting adequate sample volumes to quantify each of the depleted levels and to automate that collection as much as possible were important goals. The identified sampling locations, the types of samplers and sample durations for the Alpha (tested first) and Bravo EVS trains are summarized in Table 2. Samples locations that were moved between tests are those locations that depend on which train of the emergency ventilation systems are operating. The table indicates the number of samples taken and their flow rate. The BATS were used for automated sampling at 35 locations during the 24-hour test period. The sample duration and flow rate (ranging from two to five hours and 50 to 450 $\mathrm{ml} / \mathrm{min}$ ) were selected based on the expected concentrations.

Table 2 provides the sample quantity, duration, rates, and locations. In the Table the following acronyms were used: Return Air (RA); Supply Air (SA, Switchgear (SWGR); CBEVS (control building emergency ventilation system); HEPA (high efficiency particulate air); recirculation (Recirc); Aux (Auxiliary Building); and Control Room Emergency Ventilations System (CREVS). 
Table 2 Sampling Systems and Sample Quantity*, Duration*, Rates, and Locations

\begin{tabular}{cccccc}
$\begin{array}{l}\text { Location } \\
\text { Number }\end{array}$ & Location & $\begin{array}{l}\text { Number } \\
\text { of } \\
\text { samples* }\end{array}$ & $\begin{array}{l}\text { Time } \\
\text { (hours)* }\end{array}$ & $\begin{array}{l}\text { Flow } \\
\text { 2000' Elevation } \\
(\mathrm{ml} / \mathrm{min})\end{array}$ & Comments \\
\hline & & & & \\
& & & & & \\
1 & El 2000 Active RA Grill & 12 & 2 & 100 & Move between tests \\
2 & El 2000 Active SA Grill & 12 & 2 & 100 & Move between tests \\
3 & El 2000 SWGR 1-1 & 12 & 2 & 100 & \\
4 & EL 2000 SWGR 1-2 & 12 & 2 & 100 & \\
5 & EL 2000 SWGR 2-1 & 12 & 2 & 100 & \\
6 & EL 2000 SWGR 2-2 & 12 & 2 & 100 &
\end{tabular}

\begin{tabular}{|c|c|c|c|c|c|}
\hline \multicolumn{6}{|c|}{ 2016' Elevation } \\
\hline 7 & EL 2016 Active RA grill & 12 & 2 & 100 & \\
\hline 8 & EL 2016 - SWBD-1 & 12 & 2 & 100 & \\
\hline 9 & EL 2016-SWBD-2 & 12 & 2 & 100 & \\
\hline 10 & EL 2016-SWBD-3 & 12 & 2 & 100 & \\
\hline 11 & El 2016-SWBD-4 & 12 & 2 & 100 & \\
\hline 12 & EL-2016 CBEVS Inlet & 12 & 2 & 100 & Move between tests \\
\hline 13 & $\begin{array}{l}\text { EL } 2016 \text { CBEVS Outlet } \\
\text { before HEPA }\end{array}$ & 6 & 4 & 450 & Move between tests \\
\hline 14 & $\begin{array}{l}\text { EL } 2016 \text { CBEVS Outlet } \\
\text { after HEPA }\end{array}$ & 6 & 4 & 450 & Move between tests \\
\hline 15 & EL 2016 CB Rercirc & $8 / 2$ & $2 / 4$ & 450 & Move between tests \\
\hline \multicolumn{6}{|c|}{ 2032' Elevation } \\
\hline 16 & EL 2032 Active RA Grill & 12 & 2 & 100 & $\begin{array}{l}\text { Move between } \\
\text { tests }\end{array}$ \\
\hline 17 & El $2032-1$ & 12 & 2 & 100 & \\
\hline 18 & EL 2032-2 & 12 & 2 & 100 & \\
\hline 19 & EL 2032-3 & 12 & 2 & 100 & \\
\hline \multicolumn{6}{|c|}{ Control Room } \\
\hline 20 & CR RA Grill \#1 & $8 / 2$ & $2 / 4$ & 450 & \\
\hline 21 & CR RA Grill \#2 & $8 / 2$ & $2 / 4$ & 450 & \\
\hline
\end{tabular}




\begin{tabular}{|c|c|c|c|c|c|}
\hline 22 & $\begin{array}{l}\text { CR Back of instrument } \\
\text { panel near door }\end{array}$ & 6 & 4 & 450 & \\
\hline 23 & $\begin{array}{l}\text { CR Back of instrument } \\
\text { panel down hallway }\end{array}$ & 6 & 4 & 450 & \\
\hline \multicolumn{6}{|c|}{ Auxiliary Building } \\
\hline 24 & Aux - near CREVS & 6 & 4 & 300 & Move between tests \\
\hline 25 & $\begin{array}{c}\text { Aux - CREVS inlet } \\
\text { before HEPA }\end{array}$ & 6 & 4 & 300 & Move between tests \\
\hline 26 & $\begin{array}{c}\text { Aux - CREVS inlet after } \\
\text { HEPA }\end{array}$ & 6 & 4 & 300 & Move between tests \\
\hline 27 & $\begin{array}{c}\text { Aux - CREVS outlet } \\
\text { before HEPA }\end{array}$ & $1 / 4$ & $4 / 5$ & 450 & Move between tests \\
\hline 28 & $\begin{array}{c}\text { Aux -CREVS outlet after } \\
\text { HEPA }\end{array}$ & $1 / 4$ & $4 / 5$ & 450 & Move between tests \\
\hline 29 & $\begin{array}{c}\text { Aux - Eq room Active @ } \\
300 \text { cfm RA }\end{array}$ & $8 / 2$ & $2 / 4$ & 450 & Move between tests \\
\hline 30 & $\begin{array}{l}\text { Aux - Eq room inactive } \\
\text { near RA Grill }\end{array}$ & 12 & 2 & 450 & Move between tests \\
\hline 31 & $\begin{array}{c}\text { Aux Eq Room Active } \\
\text { Near CREVS }\end{array}$ & $8 / 2$ & $2 / 4$ & 450 & Move between tests \\
\hline \multicolumn{6}{|c|}{ Elevation 2073} \\
\hline 32 & EL 2073 Active RA Grill & 12 & 2 & 100 & \\
\hline 33 & El $2073-1$ & 12 & 2 & 100 & \\
\hline 34 & EL 2073-2 & 12 & 2 & 100 & \\
\hline 35 & EL 2073-3 & 12 & 2 & 100 & \\
\hline
\end{tabular}

* For locations with multiple values for duration and number of samples, there was a change in the sampling duration during the test. For example, location 15 states that the number of samples is $8 / 2$ and the duration is $2 / 3$. This indicates that 8 samples were taken for 2 hours and 2 samples were taken for four hours. The total duration of all samples at a location is 24 hours. 


\subsubsection{Alpha Test}

Sampling for the first train, the Alpha train, commenced at 0900 on Friday August $26^{\text {th }} .1000 \mathrm{cfm}$ charcoal fans were available on the 2000 and 2016 foot elevations. $350 \mathrm{cfm}$ fans were used on the 2032 and 2073 foot elevations. To provide additional charcoal filtration, the emergency ventilation system was turned on at approximately 0245 on Friday August $26^{\text {th }}$. In additions, the fans on the 2032 and 2073 elevation were turned on at 0630 that morning and left on for 11.5 hours. This additional filtration brought the system closer to the steady-state values needed to measure in-leakage. The filtration times ae provided in Table 3.

The transition between the Alpha and Bravo train requires the normal ventilation to be started. The full transition requires time for the switch and a three-hour break between sampling for the Alpha and Bravo trains was planned. After getting the system in alignment, the pressure differential between the control room and the outside was less than the level required in the test specifications, 0.25 inches of water. Verification that the plant was in the appropriate lineup was made, but the pressure differential was still not high enough. This issue was documented in the station's corrective action program and the test on the Bravo train was terminated approximately 4 hours after it started.

A repair was made and the test of the Bravo train was re-scheduled for September $9^{\text {th }}$ and $10^{\text {th }}$.

\subsubsection{Bravo Train}

For the Bravo train the BATS were set to start at 0900 on Friday, September $9^{\text {th }}$. Sampling continued until 0900 on September $10^{\text {th }}$. The sampling plan outlined in Table 2 was followed. The operation of the Charcoal assist fans is provided in Table 3. To provide additional charcoal filtration, the emergency ventilation system was turned on at approximately 0900 on Thursday September $8^{\text {th }}$.

Table 3. Charcoal Assist Operation Times

\begin{tabular}{|c|c|c|c|c|}
\hline Elevation & Date & $\begin{array}{l}\text { Time } \\
\text { On }\end{array}$ & $\begin{array}{l}\text { Time } \\
\text { Off }\end{array}$ & Duration \\
\hline 2000 & $26-\mathrm{Aug}$ & $09: 25$ & $15: 00$ & $5: 35$ \\
\hline 2016 & 26 - Aug & $09: 35$ & $15: 05$ & $5: 30$ \\
\hline 2032 & 26 - Aug & $06: 30$ & 19:00 & $11: 30$ \\
\hline 2073 & $26-\mathrm{Aug}$ & $06: 35$ & 19:05 & $11: 30$ \\
\hline CBEVS & 26 - Aug & 09:00 & $13: 00$ & $4: 00$ \\
\hline \multicolumn{5}{|c|}{ Bravo Train } \\
\hline Elevation & Date & $\begin{array}{l}\text { Time } \\
\text { On }\end{array}$ & $\begin{array}{l}\text { Time } \\
\text { Off }\end{array}$ & Duration \\
\hline 2000 & 9 -Sept & $15: 50$ & $21: 22$ & $5: 32$ \\
\hline 2016 & 9 -Sept & $15: 45$ & $21: 19$ & $5: 34$ \\
\hline 2032 & 9 -Sept & $15: 40$ & $21: 29$ & $5: 49$ \\
\hline 2073 & 9 -Sept & $15: 33$ & $21: 25$ & $5: 52$ \\
\hline CBEVS & 9 -Sept & $15: 15$ & 19:00 & $3: 45$ \\
\hline
\end{tabular}




\section{$\underline{2.3 \text { Perfluorocarbon Tracers }}$}

The PFT method usually consists of the tracers themselves, injection techniques, samplers, and analyzers. In the Atmospheric Tracer Depletion test performed at Wolf Creek no additional tracers are introduced. Instead, the background levels of the PFTs are reduced when passing through a charcoal filter. The difference between levels of tracer depleted from ambient air and the levels measured in the CR allows a measure of in-leakage of unfiltered air. PFTs have the following advantages over conventional tracers:

- PFTs exist in normal ambient air and are removed by the EVS charcoal filtration system which allows calculation of tracer depletion, allowing measurement of UI without the need for any additional tracers

- PFT technology is the most sensitive of all non-radioactive tracer technologies and concentrations in the range of parts per quadrillion $\left(1\right.$ in $\left.10^{15}\right)$ are routinely measured. With large sample sizes the detection limit can be as low as 1 part in $10^{18}$.

- The PFTs technology is a multi-tracer technology permitting up to eleven PFTs (Table 4) to be simultaneously deployed, sampled, and analyzed with the same instrumentation. This results in multiple lines of reasoning to confirm the predicted in-leakage in a tracer depletion test. All eleven PFTs can be analyzed in fifteen minutes on a specially designed laboratory-based gas chromatograph.

PFTs have a stable background. Charcoal filtration in the EVS removes PFTs from air with varying efficiency depending on the volatility of the PFTS. The more volatile, lower molecular weight compounds are removed less efficiently than the lower volatility higher molecular weight compounds.

Table 4 Chemical Acronym, Name, and Formula for PFT Tracers

\begin{tabular}{|l|l|l|}
\hline Chemical Acronym & Chemical Name & $\mathrm{Chemical}_{\text {Formula }}$ \\
\hline PDCB $^{1}$ & Perfluorodimethylcyclobutane & $\mathrm{C}_{6} \mathrm{~F}_{12}$ \\
\hline PMCP $^{1}$ & Perfluoromethylcyclopentane & $\mathrm{C}_{6} \mathrm{~F}_{12}$ \\
\hline PMCH & Perfluoromethylcyclohexane & $\mathrm{C}_{7} \mathrm{~F}_{14}$ \\
\hline oc-PDCH $^{2}$ & ortho-cis-perfluorodimethylcyclohexane & $\mathrm{C}_{8} \mathrm{~F}_{16}$ \\
\hline mt-PDCH $^{2}$ & Meta-trans-perfluorodimethylcyclohexane & $\mathrm{C}_{8} \mathrm{~F}_{16}$ \\
\hline pc-PDCH $^{2}$ & Para-cis--perfluorodimethylcyclohexane & $\mathrm{C}_{8} \mathrm{~F}_{16}$ \\
\hline otPDCH $^{2}$ & Othro-trans- perfluorodimethylcyclohexane & $\mathrm{C}_{8} \mathrm{~F}_{16}$ \\
\hline mc-PDCH $^{2}$ & Meta-cis-dimethylcyclohexane & $\mathrm{C}_{8} \mathrm{~F}_{16}$ \\
\hline pt-PDCH & Perfluorotrans 1,4 dimethylcyclohexane & $\mathrm{C}_{8} \mathrm{~F}_{16}$ \\
\hline PTCH & Perfluorotrimethylcyclohexane & $\mathrm{C}_{9} \mathrm{~F}_{18}$ \\
\hline iPPCH & Perfluoro-iso-propocyclohexane & $\mathrm{C}_{9} \mathrm{~F}_{18}$ \\
\hline
\end{tabular}

${ }^{1}$ Chemically distinct isomers

${ }^{2}$ Chemically distinct isomers

In a typical tracer depletion test the four PDCH isomers ( $\mathrm{mt}, \mathrm{pc}, \mathrm{mc}$, and pt-PDCH) are used in the analysis. Charcoal filters capture only about $90 \%$ of the PDCB and PMCP and thus, they are not acceptable for determining depletion below this level and cannot be used in tracer depletion tests. $\mathrm{PMCH}$ and ocPDCH typically show greater than 95\% removal and can be used if necessary when 
in-leakage leads to concentrations much greater than $5 \%$ of their background values. The four PDCH's selected for use typically have $>99.5 \%$ removal by the charcoal filter and this makes them suited for cases when in-leakage is low and the depleted concentration is near $1 \%$ of the background value.

In the Alpha test, analytical issues with the gas chromatogram (GC) provided unreliable readings for $\mathrm{mt}, \mathrm{pc}$, and $\mathrm{mt}-\mathrm{PDCH}$. For this reason, $\mathrm{PMCH}$ and $\mathrm{mc}-\mathrm{PDCH}$ were used to determine inleakage in the Control Building. The higher amount of bypass of PMCH through the charcoal filter makes this tracer unusable in the Control Room and Auxiliary Buildings where the depleted concentrations is less than 5\%. Prior to performing the gas chromatogram analysis for samples in these buildings, the operations of the GC were optimized to remove interferences of the PDCH isomers that were occurring. This included changing the reducing catalyst and changing some of the operating termperatures. For the Control Room and Auxiliary Building the four PDCH isomers (mt, pc, mc, and pt) were used.

The Bravo test data were analyzed after the optimization of the GC and the four PDCH isomers were used for analysis of in-leakage in the Control Building and the Auxiliary Building. In the Control Room interferences with $\mathrm{mt}$ and $\mathrm{pc}-\mathrm{PDCH}$ values on some of the samples required that ot-PDCH also be used as a measure of in-leakage. ot-PDCH is typically not used as the other four tracers should provide adequate confirmation of in-leakage. This was not the case for the Control Building and thus ot-PDCH was included. 


\subsection{Results}

All samples were analyzed and the computations to translate the measurements of the gas chromatograph to concentration were performed. This report provides results based on interpretation of PMCH and mcPDCH for the Control Building (CB) in the Alpha test and four isomers of PDCH for the Control Room (CR) in the Alpha test. In the Bravo tests, four isomers of PDCH were used in the $\mathrm{CB}$ and five isomers in the $\mathrm{CR}$. A discussion of the selection of tracers used is presented when discussing the data. This section provides an evaluation of whether steady-state was reached and the concentrations measured in the CB, CR, Equipment Rooms (ER), at the exhaust of the charcoal filter system, and at background. These concentrations are used to estimate in-leakage and the results are presented. Comparisons between different tracers were checked for consistency and found to generally be within a few percent. Exceptions to this are discussed later in the report with the data presentation.

\subsection{Approach to Steady-State Concentrations}

Since automatic samples were collected using the BATS over 1- to 5-hr durations for the $24 \mathrm{hr}$ Atmospheric Tracer Depletion tests, it was possible to observe the results approaching steady state. The calculations of in-leakage (Section 3.3) assume that steady-state conditions have been attained. If the data collection is completed before steady-state has been reached, in-leakage will be conservatively over predicted

Figures 1 and 2 show the approach to steady-state for the BATS located at the 2000 Elevation labeled Switchgear 1-1 (Location 3 in Table 2). BATS 3 was used at this location in the Alpha test and BATS 4 was used in the Bravo test. Both figures plot the fractional depletion of each tracer over time. The fractional depletion is the concentration of the tracer divided by the background concentration of that tracer. This normalization allows a direct comparison between different tracers. Assuming that the charcoal filter effectively removes all the tracer, the different tracers should provide identical results. The excellent match between tracers is evident in Figures 1 and 2. In Figure 1, the concentrations decrease rapidly during the first six hours when the extra charcoal assist fans were operating. After that time, the concentrations decrease slowly appearing to be close to steady-state after approximately twenty hours. Similar graphs could be provided for the data from other BATS units in the analysis. Appendix 1 lists all the data collected in this report and can be used to confirm that steady-state is reached. 


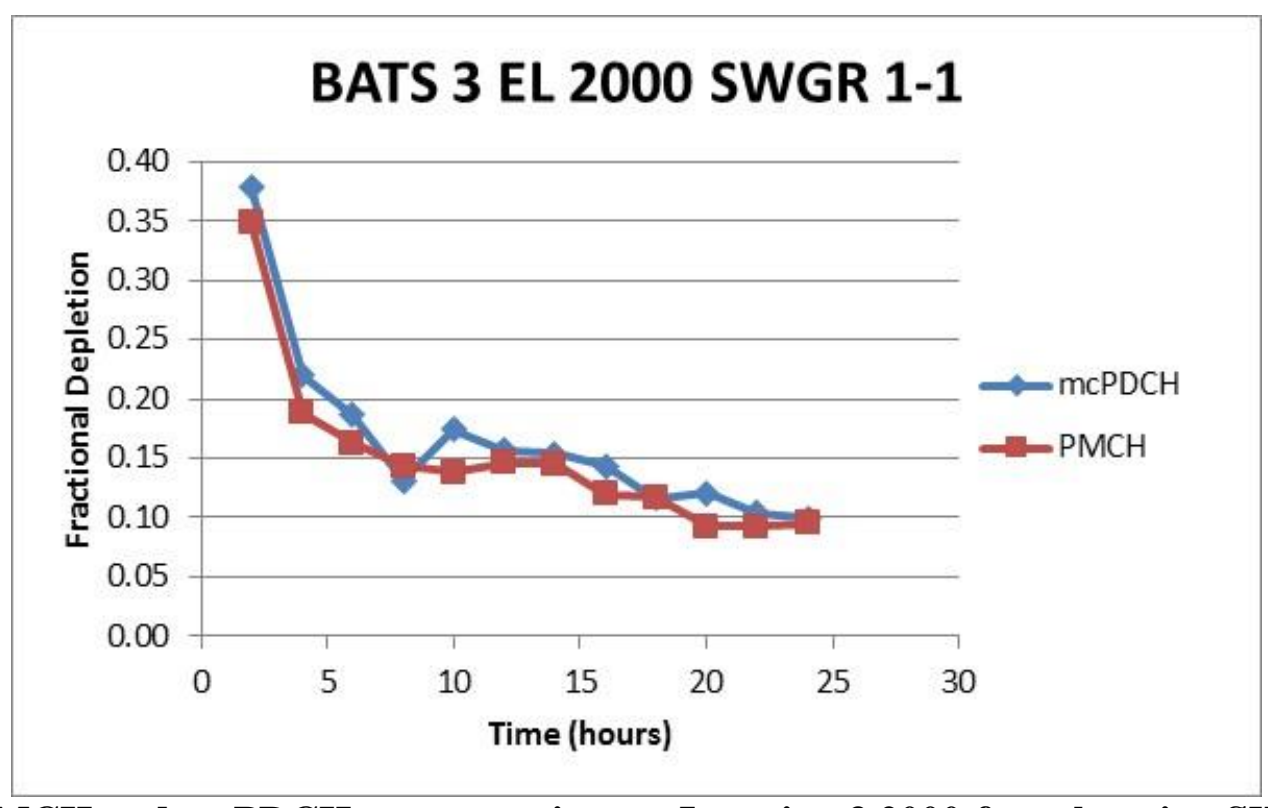

Figure 1 PMCH and mcPDCH concentrations at Location 3 2000-foot elevation SWGR 1-1

Figure 2 shows the concentration of the four $\mathrm{PDCH}$ isomers over time at this same location. In the Bravo test BATS 4 was used to collect the data. Note that the concentrations in the Bravo test at the first data point were significantly lower (Alpha test initial point $\sim 0.36$, Bravo test $\sim 0.28$ ). This is due to the earlier start time of the EVS in the Bravo test. At this lower starting value, the concentrations overshot the equilibrium level when the additional charcoal fans were turned on. They later rebounded up to the steady-state values and approached steady-state at the end of the test. Also, note, that the steady-state concentrations in the switchgear room are higher in the Bravo test ( 0.14 versus the Alpha test $\sim 0.1)$ indicating higher in-leakage in this room during the Bravo test.

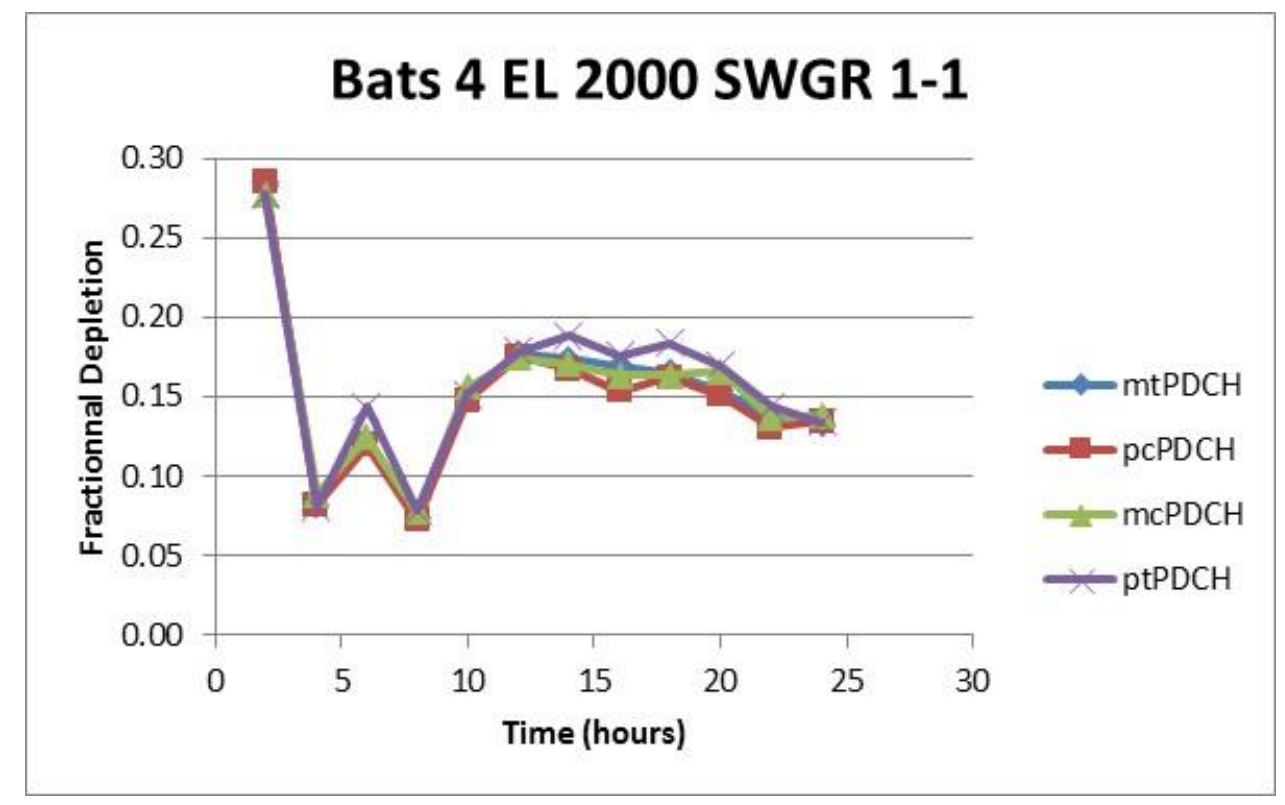

Figure 2 PDCH isomers tracer concentrations at Location 3 2000-foot elevation SWGR 1-1. 


\section{$\underline{3.2 \text { Concentrations }}$}

\section{$\underline{\text { 3.2.1 Background Concentrations }}$}

In this report, the concentrations are reported in units of Area/L. The Area is the area under the curve of the peak on the GC output. This value could be translated to fL/L which would represent the femtoliters $\left(10^{-15} \mathrm{~L}\right)$ of PFT per liter of air using the known standards that are analyzed with the samples. This step is omitted in this report because everything is normalized to the background concentration reported in units of Area/L. Thus, the key analysis parameter, $F_{\text {dep }}$, is the sample concentration in Area/L divided by the background concentration in Area/L. At the low concentrations in this test, the relationship between Area/L and $\mathrm{fL} / \mathrm{L}$ is linear and no further calculations are required. In a few cases, the measured Areas were high enough to enter the nonlinear response range. In these cases, the concentration in $\mathrm{fL} / \mathrm{L}$ was calculated to determine $\mathrm{F}_{\text {dep. }}$.

To accurately determine depletion of ambient PFTs it is critical to have an accurate determination of those levels before any filtration occurs. These ambient background concentrations were obtained from the BATS sampler that was placed on the inlet of the CBEVS which takes outside air and passes it through the charcoal filter. These concentrations are the values found everywhere before the charcoal systems are turned on. Figure 3 shows the background concentrations for the Alpha test. The twelve background concentrations are summarized in Table 5 in terms of the average concentration in GC response in area for each per liter of air, standard deviation, and percentage variation in standard deviation.

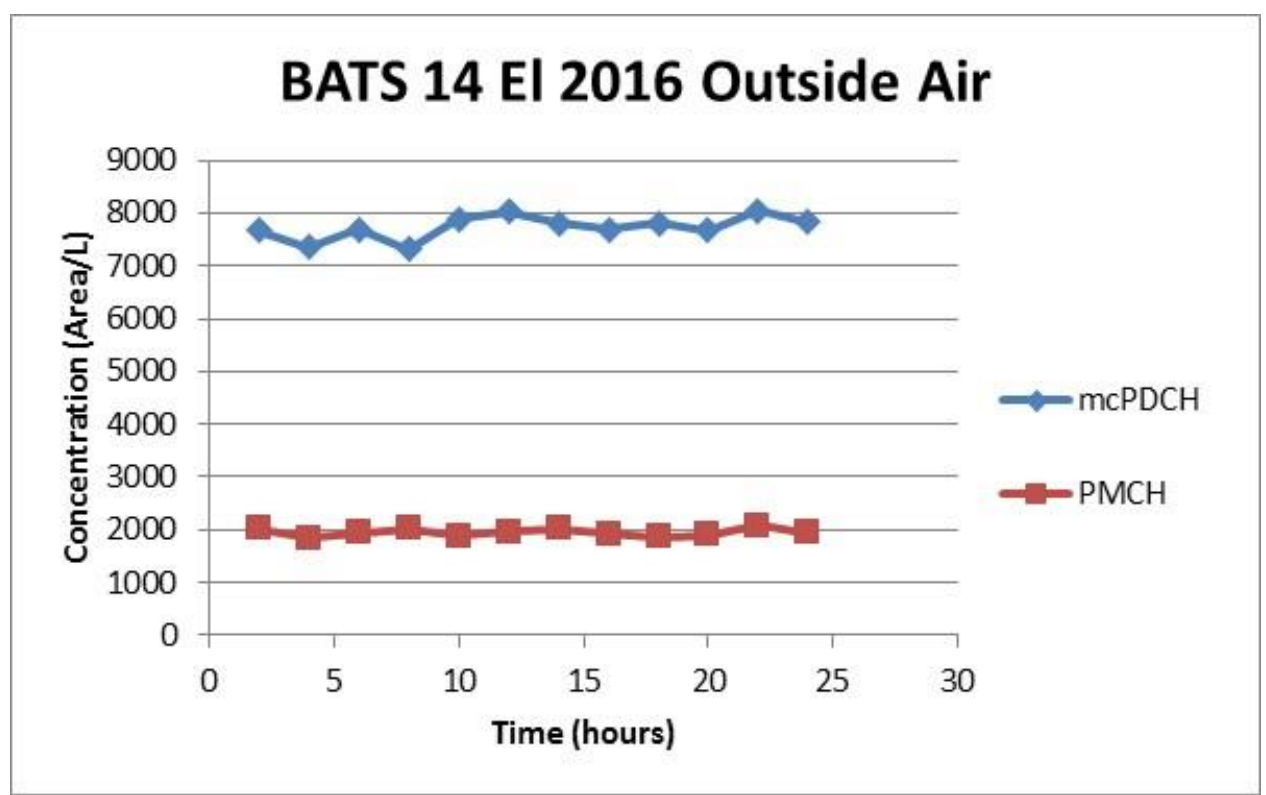

Figure 3 Outside air (background) concentrations for PMCH and mcPDCH.

Table 5 Background Concentrations (Area/L) in the Alpha Test.

\begin{tabular}{lcc} 
& PMCH & mcPDCH \\
\hline Average (Area/L) & 2209.3 & 7735.1 \\
Standard Deviation & 150.7 & 227.6 \\
\% Standard deviation & 6.8 & 2.9
\end{tabular}


In the Bravo test five different PDCH isomers were used in the analysis of in-leakage. Their background values based on eight samples is provided in Table 6. These samples were analyzed after optimization and the GC response increased the measured response (Area/L) for mcPDCH by about $50 \%$.

Table 6 Background concentrations (Area/L) measured during the Bravo tests.

\begin{tabular}{lccccc} 
& pcPDCH & mtPDCH & otPDCH & mcPDCH & ptPDCH \\
\hline Average (Area/L) & 11904 & 8439 & 1147 & 11982 & 6973 \\
Standard Deviation & 824 & 475 & 69 & 1229 & 1067 \\
\% Standard Deviation & 6.9 & 5.6 & 6.0 & 10.3 & 15.3
\end{tabular}

During the analysis phase of the test the Electron Capture Device on the GC failed. It was replaced and this also increased the detector response. The number of area counts increased on known standards. To address this, additional background air samples collected on Long Island were used to determine the background level. Comparing the known standards with the Long Island background data showed that it was a good surrogate for the Wolf Creek background. This is expected because the background of PFTs well mixed in the Northern Hemisphere. After the replacement of the Electron Capture Device, a 12-liter Long Island air sample was analyzed with each set of samples to confirm that the response was not changing. Known standards were analyzed with each set of data for all data in this test.

\subsubsection{Control Building Concentrations}

Sampling in the CB was performed using four to seven BATS at each of the four elevations in the CB envelope (Table 2). The background concentrations (Tables 5 and 6) of the different tracers differ by more than an order of magnitude. To judge the consistency between the four tracers it is more convenient to examine the fractional depletion $\left(\mathrm{F}_{\mathrm{dep}}\right)$, defined as the measured value divided by the background value. $F_{\text {dep }}$ is used in the equations for in-leakage as will be discussed in Section 3.3. Recall that the backgrounds provided in Table 5 and 6 are in Area/L and a count of 10,000 in units of Area/L is approximately $10 \mathrm{fL} / \mathrm{L}$ (or 1 part in $10^{15}$ ) depending on the tracer.

The different GC operating conditions required care when normalizing the data. The $\mathrm{F}_{\text {dep }}$ results of the Alpha test data analyzed prior to the failure of the Electron Capture Device were normalized using the background data analyzed just prior to the analysis of this group of data. The $F_{\text {dep }}$ results after the failure of the Electron Capture Device were normalized to background data from the plant and from Long Island that were compared to known standards. This approach insured that the normalization procedure used data analyzed under the same operating conditions.

Figure 4 shows a typical time evolution of the two tracers in the Lower Cable Spreading Room (LCSR) on the 2032-foot elevation for the Alpha test. The graph plots the normalized concentration, $F_{\text {dep }}$, versus time after the start of the Alpha test. The concentrations appear to be near steady-state in this example after about 15 hours. In the analysis, the last 3 samples (6 hours of data) are used to calculate average $\mathrm{F}_{\text {dep. }}$ 


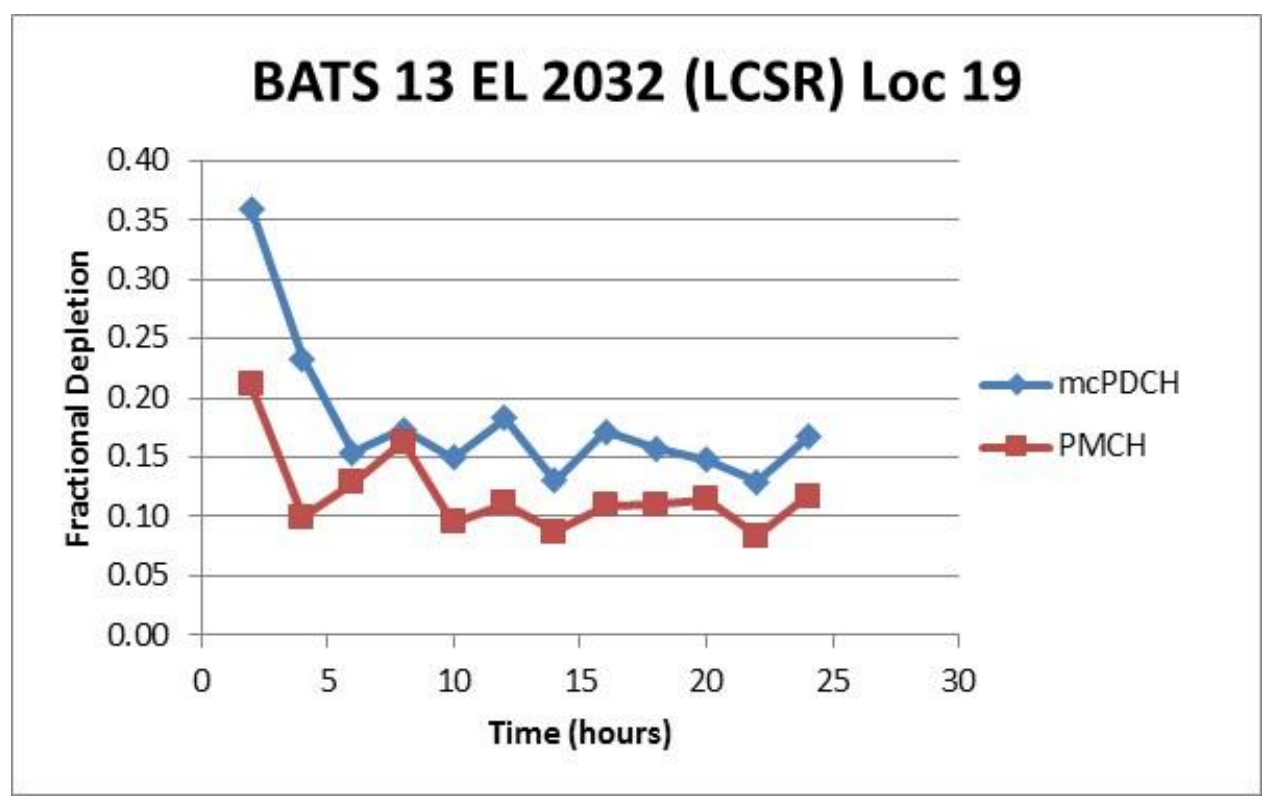

Figure 4 Time-dependent mcPDCH concentration at Elevation 2032.

Table 7 presents the average $F_{\text {dep }}$ during the last six hours of the Alpha test along with the average for the two tracers used in the Alpha test, the standard deviation between the tracer $F_{\text {dep }}$, and the percentage difference defined as 100 multiplied by the standard deviation and divided by the average.

Table 7 CB Fractional depletion in the Alpha Test

\begin{tabular}{|l|c|c|c|c|c|}
\hline & PMCH & mcPDCH & Avg & Std Dev & $\%$ Diff \\
\hline El 2000 & 0.13 & 0.18 & 0.16 & 0.038 & 24.4 \\
\hline El 2016 & 0.13 & 0.21 & 0.17 & 0.056 & 32.8 \\
\hline El 2032 & 0.09 & 0.14 & 0.12 & 0.030 & 26.1 \\
\hline El 2073 & 0.10 & 0.14 & 0.12 & 0.023 & 19.3 \\
\hline Average & 0.11 & 0.17 & 0.14 & & \\
\hline
\end{tabular}

Examining Table 7 the fractional depletion as measured by $\mathrm{PMCH}$ is always 30 to $50 \%$ lower than $\mathrm{mcPDCH}$. This reflects the difficulties in the GC analysis as these numbers should be much more similar. There were often interfering peaks near the $\mathrm{mcPDCH}$ value that may have been contributed to the mcPDCH peak. The levels that we are attempting to quantify to are less than 1 part in $10^{17}$. Thu,s only minor contamination of non-PFTs (e.g. carbon tetrachloride and other hydrocarbons) can cause problems. Both values were used to calculate in-leakage to provide a range in the estimate. Appendix A provides the summary for the average fractional depletion during the last six hours of the test for all BATS in the Control Building.

The analysis for the Bravo test was performed after optimization of GC performance. This data set is much better than the Alpha data set in term agreement between the four different tracers as the standard deviation is $10 \%$ or less on all four elevations. Like the Alpha test, the two Cable Spreading Rooms show lower $F_{\text {dep }}$ than found at Elevation 2000 or 2016. 
Table 8 CB Fractional depletion in the Bravo Test

\begin{tabular}{|l|c|c|c|c|c|c|c|}
\hline & mtPDCH & pcPDCH & mcPDCH & ptPDCH & Avg & Std Dev & $\%$ Diff \\
\hline El 2000 & 0.127 & 0.143 & 0.147 & 0.142 & 0.140 & 0.008 & 6.1 \\
\hline El 2016 & 0.134 & 0.153 & 0.130 & 0.159 & 0.144 & 0.014 & 10.0 \\
\hline El 2032 & 0.098 & 0.105 & 0.101 & 0.102 & 0.101 & 0.003 & 2.9 \\
\hline El 2073 & 0.096 & 0.104 & 0.091 & 0.102 & 0.098 & 0.006 & 5.9 \\
\hline Average & 0.114 & 0.126 & 0.117 & 0.126 & 0.121 & 0.006 & 5.3 \\
\hline
\end{tabular}

\subsubsection{Control Room (CR) Concentration Results}

Sampling in the CR was performed in 4 locations:

1) BATS \#40 sequential air sampling at the NW corner return air grill in the CR proper (not far from the entrance into the $\mathrm{CR}$ ),

2) BATS \#48 behind the console in the middle of the north wall in the line of sight of the door.

3) BATS \#47 behind the console in the middle of the west wall

4) BATS \#54 at the return air grill in the room behind the console.

BATS 40 and 54 collected eight, two hour samples and two, four hour samples at the end of the test. BATS 47 and 48 collected six, four hour samples. The last sample was used to determine the steadystate value in the Control Room. The optimization of the GC was performed prior to analyzing these samples and the four isomers of PDCH were used in the analysis. Table 9 shows the $\mathrm{F}_{\text {dep }}$ value on the last sample in the test. The average fractional depletion in the 2010 tests of each tracer is also presented the values from 2010. In Table 9, in the Alpha test, BATS 40 had all readings near zero and therefore the values are conservatively not reported. otPDCH values were not calculated for the Alpha test and are not reported. The BATS 47 data from the Bravo test were complicated by several interferences in the gas chromatograph results and are not reliable, for example, the concentrations are often greater on this BATS in the Control Room than the BATS in the Control Building. This cannot be correct and therefore, they were not used in the averages in Table 9. Similarly, the mtPDCH and ptPDCH values from BATS 54 are not reliable and were not used in the averaging. Values highlighted in yellow are outliers and not used in the averaging process. They were deemed outliers if the $\mathrm{F}_{\mathrm{dep}}$ value was more than a factor of 2 greater than the $F_{\text {dep }}$ value entering the charcoal filter. The air entering the charcoal filter is a combination of the two return air ducts in the Control Room and a return air duct in the Auxiliary Building room that houses the charcoal filter. Concentrations in the Auxiliary Building are higher than in the Control Room. Therefore, the value in the Control Room should be slightly lower than the value entering the charcoal filter.

Table 9 Main Control Room $F_{\text {dep }}$ values at the end of the test.

\begin{tabular}{cclllll} 
& BATS & pcPDCH & mtPDCH & otPDCH & mcPDCH & ptPDCH \\
Alpha Test & ID & $F_{\text {dep }}$ & $F_{\text {dep }}$ & $F_{\text {dep }}$ & $F_{\text {dep }}$ & $F_{\text {dep }}$ \\
\hline & 40 & N/A & N/A & N/A & N/A & N/A \\
& 47 & 0.023 & 0.051 & N/A & 0.026 & 0.020 \\
48 & 0.014 & 0.012 & N/A & 0.018 & 0.011 \\
& 54 & 0.024 & 0.045 & N/A & 0.026 & 0.015 \\
& Average & 0.020 & 0.036 & & 0.023 & 0.015
\end{tabular}


2010

\begin{tabular}{lcccccc} 
Alpha & Average & $0.0048^{1}$ & N/A $^{1}$ & N/A & 0.0062 & 0.0052 \\
\hline \multirow{3}{*}{ Bravo Test } & 40 & 0.019 & 0.036 & 0.001 & 0.017 & 0.002 \\
& 47 & 0.068 & 0.283 & 0.015 & 0.044 & 0.002 \\
& 48 & 0.002 & 0.016 & 0.002 & 0.002 & 0.006 \\
& 54 & 0.033 & 0.143 & 0.009 & 0.017 & 0.148 \\
& Average $^{2}$ & 0.018 & 0.026 & 0.004 & 0.012 & 0.004
\end{tabular}

2010

0.018

Bravo

Average

$0.0013^{1}$

$\mathrm{N} / \mathrm{A}^{1}$

0.0027

0.0013

${ }^{1}$ In the 2010 tests, pc and mtPDCH were reported together.

${ }^{2}$ Values highlighted in yellow omitted from the average.

Comparing the results in Table 9 from 2010 and 2016 the fractional depletion is much higher in 2016. A major cause of this is breakthrough of tracers past the charcoal filters. After absorption on to the charcoal, release of the PFTs requires heating to temperatures in excess of $200{ }^{\circ} \mathrm{C}$. Thus, the breakthrough cannot be attributed to release from the charcoal. On a new filter, the $F_{\text {dep }}$ value for each PDCH isomer should be less than 0.001. This was the case in 2004 and 2010. In 2016 the $F_{\text {dep }}$ values were much higher exiting the charcoal filter. Table 10 provides the $F_{\text {dep }}$ value for BATS 91 which was located at the exhaust of the charcoal filter beyond the HEPA filter. This is the supply air after filtration for the Control Room. In general, the Alpha train charcoal filter was showing between 1 and $4 \%$ breakthrough. The Bravo train charcoal filter was better showing 0.1 to $1.5 \%$ breakthrough. The breakthrough was higher than the $\mathrm{F}_{\text {dep }}$ values in 2010.

Table 10 Air concentrations after leaving the charcoal filter in the Auxiliary Building (BATS 91).

\begin{tabular}{rcccccc} 
& Test & pcPDCH & mtPDCH & otPDCH & mcPDCH & ptPDCH \\
BATS 91 & & $\mathrm{F}_{\text {dep }}$ & $\mathrm{F}_{\text {dep }}$ & $\mathrm{F}_{\text {dep }}$ & $\mathrm{F}_{\text {dep }}$ & $\mathrm{F}_{\text {dep }}$ \\
\hline & Alpha & 0.019 & 0.038 & N/A & 0.021 & 0.010 \\
& Bravo & 0.004 & 0.015 & 0.001 & 0.003 & 0.004
\end{tabular}

To account for breakthrough of the charcoal filter, the values in Table 10 are subtracted from those in Table 9 to give a best estimate of the increase in concentration due to in-leakage. In cases where the adjusted $F_{\text {dep }}$ value is less than zero, it is set to 0.002 . Table 11 presents the adjusted $F_{\text {dep }}$ values in the Control Room. The values in Table 11 are used to calculate in-leakage. 
Table 11 Main Control Room Fdep values at the end of the test adjusted for breakthrough

\begin{tabular}{|c|c|c|c|c|c|c|}
\hline Alpha Test & $\begin{array}{c}\text { BATS } \\
\text { ID }\end{array}$ & $\begin{array}{c}\text { pcPDCH } \\
\mathrm{F}_{\mathrm{dep}}\end{array}$ & $\begin{array}{c}\mathrm{mtPDCH} \\
\mathrm{F}_{\mathrm{dep}}\end{array}$ & $\begin{array}{c}\text { otPDCH } \\
\mathrm{F}_{\mathrm{dep}}\end{array}$ & $\begin{array}{c}\mathrm{mcPDCH} \\
\mathrm{F}_{\mathrm{dep}}\end{array}$ & $\begin{array}{c}\text { ptPDCH } \\
F_{\text {dep }}\end{array}$ \\
\hline & 40 & N/A & N/A & N/A & N/A & N/A \\
\hline & 47 & 0.004 & 0.012 & N/A & 0.003 & 0.011 \\
\hline & 48 & $0.002^{1}$ & $0.002^{1}$ & N/A & $0.002^{1}$ & 0.001 \\
\hline & 54 & 0.006 & 0.007 & N/A & 0.003 & 0.005 \\
\hline & Average & 0.0041 & 0.0071 & & 0.0027 & 0.0057 \\
\hline \multicolumn{7}{|l|}{2010} \\
\hline Alpha & Average & $0.0048^{1}$ & $\mathrm{~N}^{\prime} \mathrm{A}^{1}$ & N/A & 0.0062 & 0.0052 \\
\hline \multirow[t]{4}{*}{ Bravo Test } & 40 & 0.015 & 0.021 & 0.0004 & 0.014 & $0.002^{1}$ \\
\hline & 48 & $0.002^{1}$ & 0.001 & 0.001 & $0.002^{1}$ & 0.002 \\
\hline & 54 & 0.029 & & 0.008 & 0.014 & \\
\hline & Average & 0.015 & 0.011 & 0.003 & 0.010 & 0.002 \\
\hline 2010 & & & & & & \\
\hline Bravo & Average & $0.0013^{1}$ & N/A ${ }^{1}$ & & 0.0027 & 0.0013 \\
\hline
\end{tabular}

${ }^{1}$ Values with an adjusted $F_{\text {dep }}$ of less than 0 were set to 0.002.

\subsubsection{Equipment Room Concentrations}

During each test, four BATS were placed on the CREVS unit. BATS 93 at the inlet of the system prior to the first HEPA filter, BATS 94 downstream of the first HEPA filter, BATS 84 just after the charcoal filter and BATS 91 immediately after the second HEPA filter. The expected results from these BATS would be that the depletion prior to the charcoal would be greater than the depletion in the samples after the charcoal. This was observed for each unit except BATS 84 on both trains. Due to concerns over particulate from the sample immediately downstream of the charcoal bed, an additional filter was placed in the tubing leading to BATS 84. It is likely that small amounts of air from the Auxiliary room entered the air flow at the connection of this additional filter and skewed the results of these samples to higher concentrations at this location than the other three. The air sample from BATS 91 represents the air that has passed through filtration and is recirculated in the Control Room. Table 12 presents the best estimate for the steady-state concentration at each of these locations in the Alpha and Bravo test. The Alpha test shows higher concentrations throughout. This is partially due to the higher breakthrough as discussed previously. Similar to the Control Room data, the $F_{\text {dep }}$ values are adjusted for breakthrough by subtracting the $F_{\text {dep }}$ values at BATS 91. Table 13 provides the adjusted $F_{\text {dep }}$ value. Even with the correction, the Alpha test shows higher $F_{\text {dep }}$ values suggesting more in-leakage into the Auxiliary room or Control Room. 
Table 12 BATS Fdep values on the Auxiliary Room CREVS system

\begin{tabular}{clcccc} 
BATS & Location & mtPDCH & pcPDCH & mcPDCH & ptPDCH \\
\hline & Alpha Test & & & & \\
93 & Aux in before HEPA & 0.056 & 0.097 & 0.072 & 0.071 \\
94 & Aux in after HEPA & 0.037 & 0.062 & 0.065 & 0.082 \\
84 & AUX After Charcoal Filter & 0.092 & 0.073 & 0.133 & 0.065 \\
91 & AUX CREVS out After HEPA & 0.019 & 0.038 & 0.021 & 0.010 \\
& Bravo Test & & & & \\
93 & Aux in before HEPA & 0.019 & 0.075 & 0.023 & 0.025 \\
94 & Aux in after HEPA & 0.017 & 0.015 & 0.020 & 0.017 \\
84 & AUX After Charcoal Filter & 0.013 & 0.034 & 0.016 & 0.016 \\
91 & AUX CREVS out After HEPA & 0.003 & 0.015 & 0.003 & 0.004
\end{tabular}

Table 13 BATS Fdep values for each tracer adjusted for breakthrough on the Auxiliary Room CREVS.

\begin{tabular}{clcccc} 
BATS & Location & mtPDCH & pcPDCH & mcPDCH & ptPDCH \\
\hline & Alpha Test & & & & \\
93 & Aux in before HEPA & 0.038 & 0.058 & 0.051 & 0.062 \\
94 & Aux in after HEPA & 0.018 & 0.023 & 0.044 & 0.072 \\
84 & AUX After Charcoal Filter & 0.074 & 0.034 & 0.113 & 0.055 \\
91 & AUX CREVS out After HEPA & 0 & 0 & 0 & 0 \\
& Bravo Test & & & & \\
93 & Aux in before HEPA & 0.016 & 0.060 & 0.020 & 0.021 \\
94 & Aux in after HEPA & 0.014 & 0.000 & 0.017 & 0.013 \\
84 & AUX After Charcoal Filter & 0.010 & 0.019 & 0.013 & 0.012 \\
91 & AUX CREVS out After HEPA & 0 & 0 & 0 & 0
\end{tabular}

To measure in-leakage into the Auxiliary Rooms that house the CREVS equipment, two BATS were placed in the active Equipment Room, one underneath the supply air duct for the room (BATS 39) and the other near the operating CREVS (BATS 28) and one BATS (BATS 42) was placed in the inactive Equipment Room. BATS 81, which had tubing directly into the recirculation air pipe, failed in both tests. In this test the portable charcoal filter was placed in the active Equipment Room (Room 1512 Alpha Train CREVS and Room 1501 Bravo train CREVS). To promote mixing the door connecting the two rooms was left open and a fan was used to push air into the Bravo room during the period when the charcoal filter was running. After stopping the charcoal filter, the door between the rooms was closed. The average $F_{\text {dep }}$ adjusted for leakage past the charcoal filter over the last six hours of each test is presented in Table 13. The results show that there is poor mixing between the two rooms as the concentrations in the in-active Equipment Room are a factor of two higher than in the Active Equipment Room in the Alpha test. In the previous test in 2010, when there was no fan in 
the Inactive equipment room this disparity was much greater. Note, that two of the BATS in the Auxiliary room were analyzed prior to optimization of the GC and the Fdep values for PMCH and mcPDCH are reported. All other data includes the four PDCH isomers. In the Bravo test the concentrations were similar. In both cases the concentrations as measured by $F_{\text {dep }}$ are lower at the location immediately below the supply air duct. This makes sense as this air is mixed with the filtered air coming out of the duct. The average of the two BATS in the Active Equipment room will be used in calculating in-leakage.

Table 14 Equipment Room Concentrations Adjusted Fractional Depletion Values.

\begin{tabular}{|c|c|c|c|c|c|c|c|}
\hline Unit & $\begin{array}{l}\text { Active } \\
\text { CREVS }\end{array}$ & Location & $\mathrm{PMCH}$ & $\mathrm{mtPDCH}$ & pcPDCH & $\mathrm{mcPDCH}$ & ptPDCH \\
\hline \multicolumn{8}{|c|}{ Alpha } \\
\hline & Aux Near & Eq Room & & & \multirow{2}{*}{\multicolumn{3}{|c|}{0.12}} \\
\hline 28 & Crevs & 1512 (Alpha) & 0.16 & & & & \\
\hline 39 & $\begin{array}{l}\text { Below Supply } \\
\text { Air Duct }\end{array}$ & $\begin{array}{l}\text { Eq Room } \\
\text { Alpha RA } \\
\text { Near CREVS }\end{array}$ & & 0.056 & 0.030 & 0.079 & 0.062 \\
\hline \multirow[t]{3}{*}{42} & $\begin{array}{l}\text { AUX Inactive } \\
\text { Equipment } \\
\text { Room } \\
\end{array}$ & $\begin{array}{l}\text { In-active } \\
\text { Eq Room } \\
1501 \text { (Bravo) }\end{array}$ & 0.26 & & & 0.25 & \\
\hline & \multicolumn{7}{|c|}{ Bravo } \\
\hline & Aux Near & Eq Room & & & & & \\
\hline 28 & $\begin{array}{l}\text { Crevs } \\
\text { Below Supply }\end{array}$ & $\begin{array}{l}1501 \text { (Bravo) } \\
\text { Eq Room }\end{array}$ & & 0.097 & 0.065 & 0.127 & 0.116 \\
\hline 39 & $\begin{array}{l}\text { Air Duct } \\
\text { AUX Inactive } \\
\text { Equipment }\end{array}$ & $\begin{array}{l}\text { Bravo RA } \\
\text { In-active } \\
\text { Eq Room }\end{array}$ & & 0.027 & 0.015 & 0.037 & 0.026 \\
\hline 42 & Room & 1512 (Alpha) & & 0.077 & 0.075 & 0.097 & 0.086 \\
\hline
\end{tabular}

\subsection{In-Leakage Calculations}

The charcoal systems in the CR and CBEVSs are capable of nearly $100 \%$ removal of the PFT isomers of PDCH found in the air. In these tests, we found breakthrough of several percent for the tracers. For this reason, the $F_{\text {dep }}$ values were adjusted to account for breakthrough past the charcoal filter. Thus, after the EVSs have been running for the appropriate time, if there is no UI, the concentration of the PFTs in the envelopes will approach zero after adjustment for breakthrough. If there is a finite amount of UI, then the concentration will come to equilibrium at some low level greater than zero.

There are four zones to consider for unfiltered in-leakage: the control building (CB), the control room (CR), the active equipment room (ERa) and the in-active equipment room (ERi). At Steady-State without any extra charcoal assist, the rate of UI is given by for the control room:

$$
\mathrm{R}_{\mathrm{UI}-\mathrm{CR}}=\mathrm{R}_{\mathrm{fSA}} \cdot\left(\mathrm{C}_{\mathrm{cr}}-\mathrm{C}_{\mathrm{ch}}\right) / \mathrm{C}_{\mathrm{bg}} /\left(1-\mathrm{C}_{\mathrm{cr}} / \mathrm{C}_{\mathrm{bg}}\right)
$$

Where:

$\mathrm{R}_{\mathrm{UI}-\mathrm{CR}}$ is the unfiltered in-leakage into the control building (cfm) or control room;

$\mathrm{R}_{\mathrm{fSA}}$ is the measured supply of filtered air (cfm);

$\mathrm{C}_{\mathrm{cr}}$ is the measured concentration in the control room; 
$\mathrm{C}_{\mathrm{ch}}$ is the measured concentration in the exhaust from the charcoal filter;

$\mathrm{C}_{\mathrm{bg}}$ is the background concentration.

The term $\left(\mathrm{C}_{\mathrm{cr}}-\mathrm{C}_{\mathrm{ch}}\right) / \mathrm{C}_{\mathrm{bg}}$ is the $\mathrm{F}_{\mathrm{dep}}$ value found in Table 11. The term $\mathrm{C}_{\mathrm{cr}} / \mathrm{C}_{\mathrm{bg}}$ is the $\mathrm{F}_{\mathrm{dep}}$ values in Table 10. Naming $F_{\text {depadj }}$ as the adjusted depletion values in Table 11 and $F_{\text {depcr }}$ as the non-adjusted control room depletion values in Table 10 allows Eqn (1) to be defined as:

$$
\mathrm{R}_{\mathrm{UI}-\mathrm{CR}}=\mathrm{R}_{\mathrm{fSA}} \cdot \mathrm{F}_{\text {depadj }} /\left(1-\mathrm{F}_{\text {depcr }}\right)
$$

It is important to recognize that the depleted concentration used to calculate $F_{\text {dep }}$ is the measured concentration minus the concentration of the PFT that has passed through the charcoal filters (Section 3.2.5). This is often important for the CR because the concentrations are very low as compared to background.

At steady state (SS), the rate of UI into the Control Building is given by:

$$
\mathrm{R}_{\mathrm{UI}-\mathrm{CB}}=\mathrm{R}_{\mathrm{fSA}-\mathrm{CB}} \cdot \mathrm{F}_{\mathrm{dep}} /\left(1-\mathrm{F}_{\mathrm{dep}}\right)+\varepsilon \mathrm{R}_{\mathrm{CR}} \cdot\left(\mathrm{C}_{\mathrm{CB}}-\mathrm{C}_{\mathrm{CR}}\right) /\left(\mathrm{C}_{\mathrm{bg}}-\mathrm{C}_{\mathrm{CB}}\right)
$$

where the first term on the right accounts for the tracer depletion by the Control Building filtered supply-air (SA) rate and the second term accounts for the fraction, $\varepsilon$, of the exfiltrating Control Room pressurization air, $\mathrm{R}_{\mathrm{cr}}$, that enters the Control Building. That fraction, $\varepsilon$, could range from 0 to 1 ; thus, the calculated rate of UI will be a range rather than a discrete value. Based on the data, the concentration in the control building is much greater than in the control room and the correction for leakage through the charcoal bed is not accounted for in the analysis. Thus, Eqn (3) reduces to:

$$
\mathrm{R}_{\mathrm{UI}-\mathrm{CB}}=\left(\mathrm{R}_{\mathrm{fSA}-\mathrm{CB}}+\varepsilon \mathrm{R}_{\mathrm{CR}}\right) \cdot \mathrm{F}_{\mathrm{dep}} /\left(1-\mathrm{F}_{\mathrm{dep}}\right)
$$

The exfiltration from the Control Room acts as an additional source of filtered air to the Control Building

A material balance around the active Equipment Room, which includes the CR Filtration System, was performed with the assumption that a portion $\left(\varepsilon_{1}\right)$ of the total out-leakage $(\sim 350 \mathrm{cfm})$ from the $\mathrm{CR}$ enters the $\mathrm{ER}_{\mathrm{a}}$ in addition to the 350-cfm supplied directly from the CR air handling System plus any UI directly into that zone. The assumption is that the higher pressure in the CR will allow some fraction of its total out-leakage to enter the Equipment Rooms - perhaps more into $\mathrm{ER}_{\mathrm{i}}$ than into $\mathrm{ER}_{\mathrm{a}}$. The resulting SS solution for UI into the $\mathrm{ER}_{\mathrm{a}}$ was given by:

$$
\mathrm{R}_{\mathrm{UI}-\mathrm{ERa}}=\frac{\left[\mathrm{R}_{\mathrm{ERa}}+\varepsilon_{1} \cdot\left(\mathrm{R}_{\mathrm{UI}-\mathrm{CR}}+350\right)\right] \mathrm{F}_{\mathrm{depERa}}-\left[{ }^{8} \% \cdot \mathrm{R}_{\mathrm{ERa}}+\varepsilon_{1} \cdot\left(\mathrm{R}_{\mathrm{UI}-\mathrm{CR}}+350\right)\right] \cdot \mathrm{F}_{\mathrm{depCR}}}{1-\mathrm{F}_{\mathrm{depERa}}}
$$

where $R_{E R a}$ is the 350 -cfm rate from the Control Room Air handling system directly into ER $_{a}$ (equivalent to the $300 \mathrm{cfm}$ return from this zone back to the filtration system plus the $50 \mathrm{cfm}$ of pressurization air in this zone), the $350 \mathrm{cfm}$ is the $\mathrm{CR}$ pressurization rate, the $F_{\mathrm{dep}}$ are for the respective depleted concentration ratios, and $\varepsilon_{1}$ is defined above ( $\varepsilon_{1}$ might range from 0.1 to certainly no more than 0.6 of the total CR out-leakage entering the $\mathrm{ER}_{\mathrm{a}}$ ). The $8 / 9$ of $\mathrm{R}_{\mathrm{ERa}}$ was because the $18,000 \mathrm{cfm}$ of the CR AC system only contains 16,000 cfm of CR recycle air.

A material balance around the inactive equipment room was done assuming that a fraction $\left(\varepsilon_{2}\right)$ of the CR out-leakage and a fraction $\left(\varepsilon_{3}\right)$ of that from $\mathrm{ER}_{\mathrm{a}}$ enter the $\mathrm{ER}_{\mathrm{i}}$ along with its UI. The SS solution is: 


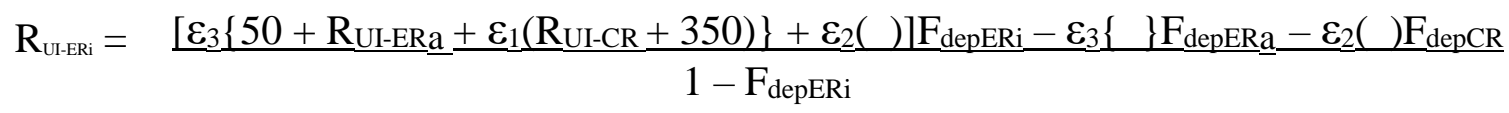

where the terms have been previously defined and the terms in the \{\} and ( ) are as first defined in the equation (i.e. \{\}$=50+\mathrm{R}_{\text {ui-Era }}+\varepsilon_{1}\left(\mathrm{R}_{\mathrm{UI}-\mathrm{CR}}+350\right)$ and ()$\left.=\mathrm{R}_{\mathrm{UI}-\mathrm{CR}}+350\right)$.

The filtered supply air rates are given in the Table 15 .

Table 15 Nominal and measured flow rates of EVS systems.

\begin{tabular}{ccc} 
EVS & Flow Path & Nominal cfm \\
\hline CB & $\begin{array}{l}\text { Outside Filtered } \\
\text { Air }\end{array}$ & 750 \\
" & Re-circulated & 1,450 \\
CR & Filtration & 2,000 \\
$"$ & Re-circulated & 1,300
\end{tabular}

Using Eqns., 2, 4, 5 and 6 the following UI rates and uncertainties were computed from the PFT concentrations in Section 3.2. For the calculations, the assumed transfer factors $\varepsilon_{1}, \varepsilon_{2}$, and $\varepsilon_{3}$ were set to 0.3 , a mid-point value in the range.

\subsubsection{Control Building Unfiltered In-Leakage}

Using Eqn 3 and the concentrations in Tables 7 (Alpha test) and 8 (Bravo test) and setting the fraction of pressurization air leaking from the Control Room into the Control Building at 0.3 the following unfiltered in-leakage (UI) rates and uncertainties were computed for the Control Building. Raising the fraction from 0.3 to 0.6 would increase the estimate for unfiltered in-leakage by 10 to $15 \%$.

The fractional depletion should be adjusted by the leakage past the charcoal filter (Table 10). This adjustment will make the fractional depletion lower and lead to a lower prediction of in-leakage. For conservatism, it is assumed that there is no leakage past the charcoal filters for the Control Building. Using the measured values after the HEPA filter would reduce the estimate of in-leakage by $5-10 \%$. The fractional depletions were calculated for the last six hours (last three samples) from the BATS data for each tracer. In the Alpha train test the tracers PMCH and mcPDCH were used. The agreement between tracers is typically within about $10 \%$. For the Alpha test the mcPDCH tracer was about $30 \%$ higher than the PMCH tracer. Table 16 presents the results for the Alpha test including the average $F_{\text {dep }}$ and calculated in-leakage Rui (cfm) along with the standard deviation in the estimate. Recall that each room has four to seven BATS that are used in the average for $F_{\text {dep. }}$. These values are used to obtain the standard deviation in $F_{\text {dep. }}$.

The in-leakage into the Control Building for the Alpha train was higher than in 2004 when it was calculated to be less than $50 \mathrm{cfm}$ for both trains. However, it was less than the value of $165 \mathrm{cfm}$ determined in 2010 for the Alpha train. There is a clear distinction between the four floors with the two upper zones (the two Cable Spreading Rooms) showing much lower in-leakage than the two lower floors. 
For the Bravo train test four isomers of PDCH were used in the analysis. The predicted in-leakage is presented in Table 17 for each isomer on each elevation. Similar to the Bravo test the two Cable Spreading Rooms showed about 25\% less in-leakage than the rooms on Elevation 2016 and 2000. The in-leakage in the Bravo test was lower than in the Alpha test and slightly lower than the 2010 test for the Bravo train (measured in-leakage of $109 \mathrm{cfm}$ ). As in the 2010 test, the Control Building in-leakage was lower in the Bravo train as compared to the Alpha train.

Table 16 Estimated Unfiltered In-leakage Rui (cfm) in the Control Building for the Alpha test.

\begin{tabular}{llcc}
\multicolumn{1}{c}{ Tracer 1 PMCH } & $\begin{array}{c}\text { Average } \\
\text { F }_{\text {dep }}\end{array}$ & $\begin{array}{c}\text { Calculated } \\
\text { Rui (cfm) }\end{array}$ \\
\hline EL 2000 & Switchgear Rooms & $0.13 \pm 0.028$ & $95.9 \pm 17.8$ \\
EL 2016 & CBEVS and Battery Rooms & $0.13 \pm 0.009$ & $97.4 \pm 5.6$ \\
EL 2032 & Lower Cable Spreading Room & $0.09 \pm 0.008$ & $70.0 \pm 6.1$ \\
EL 2073 & Upper Cable Spreading Room & $0.1 \pm 0.023$ & $77.0 \pm 15.5$ \\
& Average of all floors & $0.11 \pm 0.2$ & $85.1 \pm 13.7$
\end{tabular}

Tracer $2 \mathrm{mcPDCH}$

\begin{tabular}{llcc} 
Elevation & & $\begin{array}{c}\text { Average } \\
\mathrm{F}_{\text {dep }}\end{array}$ & $\begin{array}{c}\text { Calculated } \\
\text { Rui (cfm) }\end{array}$ \\
\hline EL 2000 & Switchgear Rooms & $0.18 \pm 0.04$ & $126.2 \pm 24.3$ \\
EL 2016 & CBEVS and Battery Rooms & $0.21 \pm 0.02$ & $141.8 \pm 8.3$ \\
EL 2032 & Lower Cable Spreading Room & $0.14 \pm 0.02$ & $102.9 \pm 10.4$ \\
EL 2073 & Upper Cable Spreading Room & $0.14 \pm 0.03$ & $102.9 \pm 15.8$ \\
& Average of all floors & $0.16 \pm 0.04$ & $103.0 \pm 20.8$ \\
& & & \\
& & & \\
& Average of all tracers & $0.14 \pm 0.04$ & $118.5 \pm 16.8$
\end{tabular}


Table 17 Estimated Unfiltered In-leakage Rui (cfm) in the Control Building for the Bravo test

Tracer $1 \mathrm{mtPDCH}$ last 6 hours

\begin{tabular}{lllr} 
Elevation & \multicolumn{1}{c}{$\begin{array}{c}\text { Measured } \\
\text { Fdep }\end{array}$} & \multicolumn{1}{c}{$\begin{array}{c}\text { Calculated } \\
\text { Rui (cfm) }\end{array}$} \\
\hline EL 2000 & Switchgear Rooms & $0.127 \pm 0.026$ & $95.0 \pm 16.8$ \\
EL 2016 & CBEVS and Battery Rooms & $0.134 \pm 0.028$ & $99.1 \pm 17.2$ \\
EL 2032 & Lower Cable Spreading Room & $0.098 \pm 0.009$ & $75.3 \pm 7.0$ \\
EL 2073 & Upper Cable Spreading Room & $0.096 \pm 0.011$ & $74.4 \pm 8.4$ \\
Average & & $0.114 \pm 0.020$ & $86.0 \pm 12.9$
\end{tabular}

Tracer 2 pcPDCH

\begin{tabular}{llcr} 
Elevation & \multicolumn{1}{c}{$\begin{array}{c}\text { Measured } \\
\text { Fdep }\end{array}$} & $\begin{array}{c}\text { Calculated } \\
\text { Rui (cfm) }\end{array}$ \\
\hline EL 2000 & Switchgear Rooms & $0.143 \pm 0.013$ & $104.6 \pm 8.3$ \\
EL 2016 & CBEVS and Battery Rooms & $0.153 \pm 0.010$ & $110.7 \pm 6.3$ \\
EL 2032 & Lower Cable Spreading Room & $0.105 \pm 0.017$ & $80.1 \pm 11.2$ \\
EL 2073 & Upper Cable Spreading Room & $0.104 \pm 0.010$ & $79.7 \pm 6.42$ \\
Average & & $0.126 \pm 0.025$ & $93.8 \pm 16.2$
\end{tabular}

Bravo Test

Tracer $3 \mathrm{mcPDCH}$

\begin{tabular}{lllr} 
Elevation & & $\begin{array}{c}\text { Measured } \\
\text { Fdep }\end{array}$ & \multicolumn{1}{c}{$\begin{array}{c}\text { Calculated } \\
\text { Rui (cfm) }\end{array}$} \\
\hline EL 2000 & Switchgear Rooms & $0.147 \pm 0.033$ & $107.1 \pm 18.5$ \\
EL 2016 & CBEVS and Battery Rooms & $0.130 \pm 0.016$ & $96.5 \pm 10.1$ \\
EL 2032 & Lower Cable Spreading Room & $0.101 \pm 0.018$ & $77.3 \pm 12.3$ \\
EL 2073 & Upper Cable Spreading Room & $0.091 \pm 0.011$ & $70.8 \pm 8.4$ \\
Average & & $0.117 \pm 0.026$ & $87.9 \pm 16.8$
\end{tabular}

Tracer 4 ptPDCH

Measured Fdep

EL 2000 Switchgear Rooms

Measured

Fdep

EL 2016 CBEVS and Battery Rooms

EL 2032 Lower Cable Spreading Room

EL 2073 Upper Cable Spreading Room

Average
$0.142 \pm 0.012$
$0.159 \pm 0.031$
$0.102 \pm 0.021$
$0.102 \pm 0.023$
$0.126 \pm 0.029$

Calculated

Rui (cfm)

$$
103.9 \pm 8.9
$$

$114.6 \pm 18.3$

$78.4 \pm 14.1$

$78.4 \pm 15.9$

$93.8 \pm 18.4$

Average of all 4

$0.121 \pm 0.023$

$87.9 \pm 4.0$ 


\subsubsection{Control Room Unfiltered In-Leakage}

Using Eqn. 2 and the Control Room $F_{\text {dep }}$ values Table 11, the Control Room Unfiltered In-leakage (UI) rates were calculated and are presented in Table 18. Due to the variability between tracers only the mean values were used in the calculations. The in-leakage was higher in 2016 than in 2010. Fractional depletion values were near $1 \%$ in the Bravo test for 3 tracers. In contrast, they were always less than $0.5 \%$ in 2010 . In the Bravo tests, there were interferences around the pcPDCH to mtPDCH range in the chromatogram that may have led to higher predicted $\mathrm{F}_{\text {dep }}$ values. Other possibilities include the high rate of breakthrough of the tracers through the charcoal filter make data interpretation more uncertain due to subtraction of similar values (measured $\mathrm{F}_{\text {dep }}$ minus $\mathrm{F}_{\text {dep }}$ leaking past the charcoal) or difficulties maintaining a positive pressure differential. The test requires a positive pressure differential of 0.25 inches of water or greater between the Control Room and the outside of the Building. In starting the test there were some difficulties obtaining this pressure differential. In the Alpha test the pressure differential was over 0.3 inches of water, whereas in the Bravo test it was 0.25 inches of water. This difference may be the cause of the higher in-leakage in the Bravo test. There were no difficulties in obtaining a pressure differential greater than 0.25 in the 2010 tests.

Table 18 Estimated Unfiltered In-leakage (cfm) in the CR

\begin{tabular}{lclcccc} 
Unit & $\begin{array}{c}\text { UI }(\mathrm{cfm}) \\
\text { based on } \\
\text { pcPDCH }\end{array}$ & $\begin{array}{l}\text { UI }(\mathrm{cfm}) \\
\text { based on } \\
\text { mtPDCH }\end{array}$ & $\begin{array}{c}\text { UI }(\mathrm{cfm}) \\
\text { based on } \\
\text { otPDCH }\end{array}$ & $\begin{array}{c}\text { UI }(\mathrm{cfm}) \\
\text { based on } \\
\text { mcPDCH }\end{array}$ & $\begin{array}{c}\text { UI }(\mathrm{cfm}) \\
\text { based on } \\
\text { ptPDCH }\end{array}$ & $\begin{array}{l}\text { Average UI } \\
(\mathrm{cfm})\end{array}$ \\
\hline Alpha Avg & 8.4 & 12.9 & N/A & 7.8 & 11.4 & $10.1 \pm 2.1$ \\
Bravo Avg & 31.2 & 22.6 & 6.3 & 20.2 & 4.0 & $16.9 \pm 10.3$
\end{tabular}

For the Bravo train, UI is higher than for the Alpha train. The wide variation between the predicted UI from different tracers is reflected in the error estimate that is approximately $60 \%$ of the mean value.

\subsubsection{Equipment Room Unfiltered In-Leakage}

Equation 5 was used to estimate the active Equipment Room UI. The average UI and fractional depletion for all four tracers and all samplers were also used (Table 14). The parameter $\varepsilon_{1}$ is a measure of the fraction of the control room out-leakage that enters the active equipment room (Section 3.3). $\mathrm{R}_{\mathrm{ERa}}(\mathrm{cfm})$ is the flow of filtered air from the EVS directly into the room. The values are substantially higher than in 2010. In 2010 the estimates ranged from 4 to $6 \mathrm{cfm}$ for the Alpha Train to 5 to $8 \mathrm{cfm}$ for the Bravo Train. In 2016 the estimates for the Alpha Train range from 40 to $55 \mathrm{cfm}$ and from 20 to $30 \mathrm{cfm}$ for the Bravo train. The cause for this is the Fdep values ranging from 0.06 to 0.1 in 2016 were much higher than in 2010 (0.01 to 0.02). A higher value for $F_{\text {dep }}$ implies greater in-leakage. 
Table 19 Estimated unfiltered in-leakage in the active equipment room as a function of $\boldsymbol{\varepsilon} 1$.

\begin{tabular}{|c|c|c|c|c|c|c|}
\hline Train & $\varepsilon 1$ & $\mathrm{R}_{\mathrm{ERa}}(\mathrm{cfm})$ & $\begin{array}{l}\mathrm{R}_{\mathrm{ui}-\mathrm{CR}} \\
(\mathrm{cfm})\end{array}$ & $\mathrm{F}_{\text {dep }} \mathrm{ERa}$ & $F_{\text {dep }} \mathrm{CR}$ & $\begin{array}{l}R_{\text {ui-ERa }} \\
(\mathrm{cfm})\end{array}$ \\
\hline Alpha & 0.1 & 350 & 10.1 & 0.1 & 0.0049 & 40.1 \\
\hline \multirow[t]{2}{*}{ (ER1512) } & 0.3 & & & & & 47.6 \\
\hline & 0.5 & & & & & 55 \\
\hline \multicolumn{7}{|l|}{$\begin{array}{l}\text { Best } \\
\text { Estimate }\end{array}$} \\
\hline Bravo & 0.1 & 350 & 15.7 & 0.064 & 0.0078 & 23.2 \\
\hline (ER1501) & 0.3 & & & & & 27.6 \\
\hline & 0.5 & & & & & 31.9 \\
\hline $\begin{array}{l}\text { Best } \\
\text { Estimate }\end{array}$ & & & & & & $28 \pm 4$ \\
\hline
\end{tabular}

Equation 3 (Section 3.3) was used to estimate the in-leakage into the inactive equipment room. This room is not pressurized with $300 \mathrm{cfm}$ of filtered air, so the UI is expected to be much higher than for the active Equipment Room. That was not the case in 2016. The Inactive Equipment Room in-leakage was less than for the Active Equipment Room. This is partially because the Fdep value in the Inactive Equipment Room was similar to the value in the Active Equipment Room, indicating that these were well mixed. This suggests that the fans that operated for the first 4 hours of the test equilibrated the two rooms and there were only minor changes after the door was closed. In 2010, the door between the two rooms was closed for the entire test. For simplicity, the UI of the active equipment room was selected to be the value when $\varepsilon_{1}=0.3$. The parameter $\varepsilon_{2}$ represents the fraction of the out leakage from the active equipment room to the inactive equipment room and $\varepsilon_{3}$ represents the fraction of the out leakage from the control room to the inactive equipment room. During the Alpha train test, Equipment Room 1501 is the inactive room. During the Bravo test, Equipment Room 1512 is the inactive room.

Table 20 Estimated unfiltered in-leakage in the inactive equipment room.

\begin{tabular}{|c|c|c|c|c|c|c|c|c|}
\hline Train & $\varepsilon_{2}$ & $\varepsilon_{3}$ & $\begin{array}{l}\mathrm{R}_{\mathrm{ui}-\mathrm{CR}} \\
(\mathrm{cfm})\end{array}$ & $\begin{array}{l}F_{\text {dep- }} \\
\text { ERA }\end{array}$ & $F_{\text {dep-CR }}$ & $\begin{array}{l}\mathrm{R}_{\text {ui-Era }} \\
(\mathrm{cfm})\end{array}$ & $\begin{array}{l}\mathrm{F}_{\text {dep- }} \\
\text { ERi }\end{array}$ & $\begin{array}{l}\mathrm{R}_{\text {ui-ERi }} \\
\text { (cfm) }\end{array}$ \\
\hline
\end{tabular}

\begin{tabular}{|c|c|c|c|c|c|c|c|c|l|}
\hline Alpha & 0.3 & 0.3 & 10.1 & 0.1 & 0.0049 & 47.6 & 0.255 & 24.4 & 1501 \\
\hline Bravo & 0.3 & 0.3 & 16.9 & 0.064 & 0.0083 & 27.6 & 0.084 & 3.3 & 1512 \\
\hline
\end{tabular}


The UI into the inactive equipment room is much greater than for the active equipment room and much higher than in the control room. This is due to the absence of pressurization with filtered air. Although not shown, reducing the fraction of out leakage received by the inactive equipment room (parameters $\varepsilon_{2}, \varepsilon_{3}$ ) reduces the predicted UI. In-leakage into Equipment Room1501 when it was the inactive room is much greater than into Equipment Room 1512 in the inactive state. This is due to the much higher concentrations found in Equipment Room 1512, which may be due to not attaining steady-state.

As originally assumed, the CRE is not a single zone - there are statistically different UI rates into the CR, ER1501, and ER1512.

\section{$\underline{\text { 3.3.4 Summary of unfiltered in-leakage results }}$}

The best estimate of UI for the four rooms is provided in Table 21. In general, there was excellent agreement $(<10 \%)$ between the estimates provided by the four individual tracers in each region for the Bravo test and the CR in the Alpha tests. In the CB in the Alpha test, two tracers were used and the difference between the two tracers was about 25 to $30 \%$.

Table 21 Summary of Unfiltered In-Leakage Results

\begin{tabular}{lllll} 
& Alpha Train & \multicolumn{3}{c}{ Bravo Train } \\
Location & $\mathrm{F}_{\text {dep }}$ & $\mathrm{R}_{\mathrm{ui}}(\mathrm{cfm})$ & $\mathrm{F}_{\mathrm{dep}}$ & $\mathrm{R}_{\mathrm{ui}}(\mathrm{cfm})$ \\
\hline CB & 0.14 & $102 \pm 24$ & 0.121 & $88 \pm 4$ \\
CR & 0.0049 & $10.1 \pm 2.1$ & 0.0083 & $17 \pm 10$ \\
ER 1501 & 0.26 & $24 \pm 4$ & 0.06 & $28 \pm 4$ \\
ER 1512 & 0.01 & $48 \pm 7$ & 0.08 & $3.3 \pm 1$
\end{tabular}

\section{$\underline{\text { 3.3.5 Use of Results }}$}

Both the net fractional depletion and the UI rates reported in Table 21 are useful in determining operator exposure. The net fractional depletion is equivalent to a net fractional concentration, which is the parameter needed for exposure assessment. Table 22 shows the relative exposure normalized to the control room in the Alpha Test.

\section{Table 22 Relative Exposure Levels}

\begin{tabular}{ccc} 
& Alpha Train Test & Bravo Train Test \\
\cline { 2 - 3 } CR & 1.0 & 1.7 \\
CB & 28.6 & 24.7 \\
ER1501 (Bravo) & 53.1 & 12.2 \\
ER1512 (Alpha) & 2.0 & 16.3
\end{tabular}

During Alpha Train use, someone in ER1501 will have 53 times the exposure rate of an operator in the CR and, in ER1512, 2 times. During Bravo Train use, the CR will have 1.7 times higher exposure rate than during Alpha train use. 


\subsection{Comparison to 2004 and 2010 Test Results}

Table 23 lists the best estimate for unfiltered in-leakage (Rui) for the Control Building (CB), Control Room (CR), Active Equipment Room (Era), and Inactive Equipment Room (ERi) for both the Alpha and Bravo trains. The 2016 Bravo test showed the highest control room in-leakage of any of the tests. Although not shown here, the standard deviation in the estimated in-leakage for the Bravo Control Room in 2016 was high $(11 \mathrm{cfm})$ as compared to a few cfm in all other tests. This reflects the differences in the five tracers used in the analysis. Two tracers showed low values for in-leakage $(<7 \mathrm{cfm})$ while 3 tracers showed high values for in-leakage $(18-30 \mathrm{cfm})$. Another difference in the 2016 results is the higher in-leakage in the active equipment room and lower inleakage in the Inactive equipment room. This is partially due to improved mixing between these two rooms due to the use of fans in both rooms for the first four hours of the test and having an open door between the rooms during this mixing period. The estimated unfiltered in-leakage into the Control Building was lower than in 2010, but higher than in 2004. In all cases, the in-leakage was acceptable and within allowable NRC guidelines.

\section{Table 23 Best estimate values for unfiltered in-leakage for Wolf Creek Control Room Habitability Tests.}

\begin{tabular}{|c|c|c|c|c|c|c|c|c|}
\hline \multirow[b]{2}{*}{ Year } & \multicolumn{2}{|c|}{ Rui-CB } & \multicolumn{2}{|c|}{ Rui-CR } & \multicolumn{2}{|c|}{ Rui-ERa } & \multicolumn{2}{|c|}{ Rui-ERi } \\
\hline & $\begin{array}{l}\text { Alpha } \\
(\mathrm{cfm})\end{array}$ & $\begin{array}{l}\text { Bravo } \\
(\mathrm{cfm})\end{array}$ & $\begin{array}{l}\text { Alpha } \\
(\mathrm{cfm})\end{array}$ & $\begin{array}{l}\text { Bravo } \\
(\mathrm{cfm})\end{array}$ & $\begin{array}{l}\text { Alpha } \\
(\mathrm{cfm})\end{array}$ & $\begin{array}{l}\text { Bravo } \\
(\mathrm{cfm})\end{array}$ & $\begin{array}{l}\text { Alpha } \\
(\mathrm{cfm})\end{array}$ & Bravo \\
\hline 2016 & 102 & 88 & 10.1 & 16.9 & 48 & 28 & 24 & 3.3 \\
\hline 2010 & 165 & 109 & 11.9 & 5.0 & 5.1 & 8.8 & 68 & 25 \\
\hline 2004 & 63 & 14 & 6.9 & 10.5 & 23 & 2.1 & 32 & 5.6 \\
\hline
\end{tabular}

\subsection{Summary and Conclusions}

Testing of unfiltered in-leakage into the Control Room, Control Building, and the Equipment Rooms that contain the CREVS was measured using up to five PFTs with automated samplers that allowed the PFT concentrations to be followed over time. The data did show that near steady-state conditions were reached in all areas after fifteen to eighteen hours into each test. On the Alpha test the difference between the two tracers used in the analysis (PMCH and mcPDCH) was about 25 to $30 \%$. Technical difficulties in the gas analyses created substantial interference in the output of the chromatogram that prevented the other tracers from being used in the analysis. These interferences would have prohibited meaningful analysis of the lower concentrations found in the Control Room, Equipment Rooms and the CREVS systems. To solve these technical issues the reducing catalyst on the GC system was replaced and the system optimized for performance with the new catalyst. This change allowed for quantification of four PFTs to be used for the Control Room samples in the Alpha test and all samples in the Bravo test. The agreement of the four PFTs was generally within $10 \%$. This agreement between different tracers increases confidence in the results. 


\section{Appendix A: Data}

The equations that predict unfiltered in-leakage (Eqns $1-5$ in the body of the report) are strictly valid only if steady-state conditions have been reached. The BATS units collected data over the entire 24-hour test period for each train and can be used to evaluate if steady-state has been reached. This appendix contains all the fractional depletion $\left(F_{\text {dep }}\right)$ data used in the analysis. $F_{\text {dep }}$ is defined as the measured concentration divided by the background concentration and is the value used in all in-leakage calculations. In addition to determining if steady-state has been reached, the agreement between different tracers can be examined. An EXCEL workbook (Wolf Creek Depletion Calculations 2-17.xls) containing the calculations presented in the report.

\section{$\underline{\text { Alpha Test }}$}

Control Building Elevation 2000 (Switchgear Rooms)

BATS 3 EL 2000 SWGR 1-1

\begin{tabular}{|c|c|c|c|c|}
\hline Sample & & $\begin{array}{l}\text { Fra } \\
D e\end{array}$ & $\begin{array}{l}\text { tional } \\
\text { letion }\end{array}$ & $\begin{array}{l}\text { Stop } \\
\text { Time }\end{array}$ \\
\hline ID & & $\mathrm{PMCH}$ & $\mathrm{mcPDCH}$ & (hours) \\
\hline & 811 & 0.35 & 0.55 & 2 \\
\hline & 10129 & 0.19 & 0.33 & 4 \\
\hline & 10350 & 0.16 & 0.26 & 6 \\
\hline & 10071 & 0.14 & 0.23 & 8 \\
\hline & 10730 & 0.14 & 0.25 & 10 \\
\hline & 9147 & 0.15 & 0.25 & 12 \\
\hline & 5265 & 0.14 & 0.24 & 14 \\
\hline & 3275 & 0.12 & 0.19 & 16 \\
\hline & 3762 & 0.12 & 0.18 & 18 \\
\hline & 6114 & 0.09 & 0.14 & 20 \\
\hline & 11621 & 0.09 & 0.15 & 22 \\
\hline & 10221 & 0.10 & 0.17 & 24 \\
\hline
\end{tabular}

BATS 32 EL 2000 SWGR 1-2

$\begin{array}{rrrr}4184 & 0.23 & 0.38 & 2 \\ 1371 & 0.16 & 0.22 & 4 \\ 11817 & 0.12 & 0.19 & 6 \\ 970 & 0.09 & 0.13 & 8 \\ 2716 & 0.12 & 0.17 & 10 \\ 7505 & 0.10 & 0.16 & 12 \\ 3063 & 0.10 & 0.15 & 14 \\ 8273 & 0.10 & 0.14 & 16 \\ 8231 & 0.09 & 0.12 & 18\end{array}$




$\begin{array}{llll}6878 & 0.10 & 0.12 & 20 \\ 4996 & 0.09 & 0.10 & 22 \\ 1723 & 0.12 & 0.10 & 24\end{array}$

BATS 20 EL 2000 SWGR

$\begin{array}{rrrr}11819 & 0.40 & 0.76 & 2 \\ 11244 & 0.26 & 0.51 & 4 \\ 11201 & 0.18 & 0.39 & 6 \\ 11648 & 0.18 & 0.34 & 8 \\ 11326 & 0.18 & 0.36 & 10 \\ 10656 & 0.15 & 0.36 & 12 \\ 8450 & 0.17 & 0.32 & 14 \\ 11043 & 0.13 & 0.26 & 16 \\ 11094 & 0.12 & 0.25 & 18 \\ 10431 & 0.14 & 0.25 & 20 \\ 10758 & 0.14 & 0.24 & 22 \\ 10565 & 0.11 & 0.21 & 24\end{array}$

BATS 17 EL 2000 SWGR 2-2

$\begin{array}{rllr}9681 & 0.00 & 0.00 & 2 \\ 10470 & 0.85 & 0.57 & 4 \\ 8492 & 0.17 & 0.40 & 6 \\ 11359 & 0.18 & 0.39 & 8 \\ 2878 & 0.22 & 0.39 & 10 \\ 9444 & 0.17 & 0.34 & 12 \\ 6633 & 0.14 & 0.26 & 14 \\ 2098 & 0.15 & 0.24 & 16 \\ 10918 & 0.11 & 0.19 & 18 \\ 162 & 0.12 & 0.22 & 20 \\ 7448 & 0.11 & 0.20 & 22 \\ 3615 & 0.14 & 0.19 & 24\end{array}$

BATS 30 EL 2000 SWGR 2-1 RA Grill

$\begin{array}{rrrr}0 & 0.00 & 0.00 & 2 \\ & & 28\end{array}$




$\begin{array}{rllr}0 & 0.00 & 0.00 & 4 \\ 0 & 0.00 & 0.00 & 6 \\ 4283 & 0.42 & 0.49 & 8 \\ 11878 & 0.25 & 0.41 & 10 \\ 12307 & 0.24 & 0.40 & 12 \\ 12044 & 0.17 & 0.29 & 14 \\ 10329 & 0.02 & 0.27 & 16 \\ 10992 & 0.17 & 0.15 & 18 \\ 8749 & 0.20 & 0.32 & 20 \\ 11407 & 0.17 & 0.15 & 22 \\ 3314 & 0.13 & 0.13 & 24\end{array}$

BATS 15 EL 2000 SWGR 2-1 RA Grill

$\begin{array}{rrrr}1411 & 0.36 & 0.69 & 2 \\ 4646 & 0.43 & 0.50 & 4 \\ 9963 & 0.19 & 0.44 & 6 \\ 778 & 0.18 & 0.36 & 8 \\ 10584 & 0.28 & 0.44 & 10 \\ 10768 & 0.23 & 0.37 & 12 \\ 10729 & 0.19 & 0.21 & 14 \\ 10446 & 0.17 & 0.27 & 16 \\ 10495 & 0.14 & 0.26 & 18 \\ 10901 & 0.17 & 0.22 & 20 \\ 10785 & 0.17 & 0.22 & 22 \\ 10038 & 0.13 & 0.16 & 24\end{array}$

BATS 4 EL 2000 SWGR RA Grill

$\begin{array}{rllr}6790 & 0.43 & 0.69 & 2 \\ 2332 & 0.22 & 0.44 & 4 \\ 6515 & 0.20 & 0.30 & 6 \\ 9215 & 0.18 & 0.28 & 8 \\ 6159 & 0.17 & 0.29 & 10 \\ 11673 & 0.15 & 0.33 & 12 \\ 6111 & 0.17 & 0.25 & 14 \\ 4503 & 0.15 & 0.24 & 16 \\ 10121 & 0.15 & 0.17 & 18 \\ 3334 & 0.12 & 0.19 & 20 \\ 12396 & 0.12 & 0.16 & 22 \\ 11831 & 0.15 & 0.21 & 24\end{array}$


Control Building Elevation 2016

\begin{tabular}{lccr} 
Sample & \multicolumn{2}{c}{ Fractional Depletion } & \multicolumn{2}{l}{$\begin{array}{l}\text { Stop } \\
\text { Time } \\
\text { ID }\end{array}$} & PMCH & mcPDCH & (hours) \\
BATS 12 EL 2016 SWBD 3 & & \\
7737 & 0.32 & 0.38 & 4 \\
8770 & 0.22 & 0.32 & 6 \\
11423 & 0.25 & 0.29 & 8 \\
1559 & 0.20 & 0.28 & 10 \\
3195 & 0.16 & 0.24 & 12 \\
11554 & 0.20 & 0.23 & 14 \\
9643 & 0.11 & 0.19 & 16 \\
7950 & 0.13 & 0.17 & 18 \\
9500 & 0.14 & 0.21 & 20 \\
7513 & 0.12 & 0.17 & 22 \\
9453 & 0.10 & 0.19 & 24
\end{tabular}

BATS 35 EL 2016 SA Grill

$\begin{array}{rrrr}2303 & & & 2 \\ 6926 & 0.29 & 0.53 & 4 \\ 10670 & 0.18 & 0.39 & 6 \\ 10830 & 0.18 & 0.34 & 8 \\ 10739 & 0.00 & 0.00 & 10 \\ 11372 & 0.21 & 0.34 & 12 \\ 2523 & 0.17 & 0.29 & 14 \\ 2773 & 0.15 & 0.28 & 16 \\ 10004 & 0.16 & 0.00 & 18 \\ 10693 & 0.16 & 0.28 & 20 \\ 11203 & 0.12 & 0.22 & 22 \\ 7731 & 0.13 & 0.21 & 24\end{array}$

BATS 34 EL 2016 SWBD 1

$\begin{array}{rrrr}2303 & 0.40 & 0.76 & 2 \\ 8841 & 0.23 & 0.45 & 4 \\ 453 & 0.19 & 0.37 & 6 \\ 3329 & 0.17 & 0.26 & 8 \\ 4058 & 0.20 & 0.32 & 10 \\ 2589 & 0.18 & 0.29 & 12 \\ 7526 & 0.16 & 0.30 & 14 \\ 7369 & 0.13 & 0.25 & 16 \\ 2471 & 0.13 & 0.25 & 18 \\ 7424 & 0.14 & 0.22 & 20 \\ 4449 & 0.13 & 0.19 & 22 \\ 4359 & 0.13 & 0.20 & 24\end{array}$


BATS 27 EL 2016 SWBD 3

$\begin{array}{rrrr}11985 & 0.33 & 0.77 & 2 \\ 10400 & 0.23 & 0.65 & 4 \\ 10124 & 0.22 & 0.41 & 6 \\ 10823 & 0.16 & 0.40 & 8 \\ 10503 & 0.22 & 0.33 & 10 \\ 10461 & 0.20 & 0.36 & 12 \\ 3024 & 0.02 & 0.01 & 14 \\ 10521 & 0.16 & 0.25 & 16 \\ 10502 & 0.13 & 0.24 & 18 \\ 10995 & 0.16 & 0.23 & 20 \\ 10491 & 0.11 & 0.21 & 22 \\ 16042 & 0.15 & 0.20 & 24\end{array}$

BATS 45 EL 2016 After Charcoal

$\begin{array}{rllr}1603 & 0.36 & 0.40 & 4 \\ 9605 & 0.23 & 0.25 & 8 \\ 7450 & 0.15 & 0.16 & 12 \\ 8926 & 0.13 & 0.15 & 16 \\ 10654 & 0.13 & 0.15 & 20 \\ 1421 & 0.12 & 0.14 & 24\end{array}$

BATS 44 EL 2016 Recirc

\begin{tabular}{rrrrrr} 
& & & & \multicolumn{2}{c}{ Time } \\
6259 & 0.40 & 0.37 & 0.55 & 0.31 & 3 \\
848 & 0.31 & 0.23 & 0.38 & 0.23 & 6 \\
7702 & 0.24 & 0.19 & 0.30 & 0.18 & 9 \\
2697 & 0.20 & 0.15 & 0.25 & 0.15 & 12 \\
9732 & 0.24 & 0.17 & 0.27 & 0.16 & 15 \\
3906 & 0.24 & 0.18 & 0.28 & 0.16 & 18 \\
7284 & 0.21 & 0.17 & 0.26 & 0.14 & 21 \\
5467 & 0.18 & 0.14 & 0.23 & 0.12 & 24
\end{tabular}


Control Building Elevation 2032 (Lower Cable Spreading Room)

BATS 6 EL2032 (LCSR) Loc 17

\begin{tabular}{rrrl} 
& \multicolumn{2}{c}{ Fractional } & \multicolumn{2}{l}{ Stop } \\
Sample & \multicolumn{2}{c}{ Depletion } & \multicolumn{2}{l}{ Time } \\
ID & PMCH & mcPDCH & (hours) \\
5538 & 0.25 & 0.37 & 2 \\
10592 & 0.18 & 0.49 & 4 \\
9298 & 0.10 & 0.35 & 6 \\
559 & 0.08 & 0.16 & 8 \\
11550 & 0.01 & 0.00 & 10 \\
8803 & 0.14 & 0.14 & 12 \\
6893 & 0.10 & 0.19 & 14 \\
10724 & 0.11 & 0.13 & 16 \\
6155 & 0.09 & 0.15 & 18 \\
10019 & 0.11 & 0.15 & 20 \\
5296 & 0.08 & 0.10 & 22 \\
6904 & 0.11 & 0.09 & 24
\end{tabular}

BATS 9 EL 2032 (LCSR) Loc 18

\begin{tabular}{rrrr} 
& \multicolumn{2}{c}{ Fractional } & \multicolumn{2}{l}{ Stop } \\
Sample & \multicolumn{2}{c}{ Depletion } & \multicolumn{1}{l}{ Time } \\
ID & PMCH & mcPDCH & (hours) \\
2735 & 0.21 & 0.39 & 2 \\
1400 & 0.12 & 0.31 & 4 \\
7439 & 0.08 & 0.15 & 6 \\
1370 & 0.11 & 0.14 & 8 \\
7389 & 0.09 & 0.13 & 10 \\
5875 & 0.10 & 0.15 & 12 \\
1824 & 0.10 & 0.14 & 14 \\
430 & 0.12 & 0.16 & 16 \\
143 & 0.09 & 0.14 & 18 \\
6286 & 0.11 & 0.11 & 20 \\
2834 & 0.06 & 0.13 & 22 \\
4830 & 0.08 & 0.15 & 24
\end{tabular}

BATS 13 EL 2032 (LCSR) Loc 19

\begin{tabular}{rrrl} 
& \multicolumn{2}{c}{ Fractional } & \multicolumn{2}{l}{ Stop } \\
Sample & \multicolumn{2}{c}{ Depletion } & \multicolumn{2}{l}{ Time } \\
ID & PMCH & mcPDCH & (hours) \\
12177 & 0.21 & 0.36 & 2 \\
11922 & 0.10 & 0.23 & 4
\end{tabular}




$\begin{array}{rrrr}10856 & 0.13 & 0.15 & 6 \\ 12199 & 0.16 & 0.17 & 8 \\ 6618 & 0.10 & 0.15 & 10 \\ 12372 & 0.11 & 0.18 & 12 \\ 11568 & 0.09 & 0.13 & 14 \\ 12364 & 0.11 & 0.17 & 16 \\ 12406 & 0.11 & 0.16 & 18 \\ 10051 & 0.11 & 0.15 & 20 \\ 11874 & 0.08 & 0.13 & 22 \\ 10955 & 0.12 & 0.17 & 24\end{array}$

BATS 6 EL2032 (LCSR) Loc 17

\begin{tabular}{rrrr} 
& \multicolumn{2}{c}{ Fractional } & \multicolumn{1}{l}{ Stop } \\
Sample & \multicolumn{2}{c}{ Depletion } & \multicolumn{1}{l}{ Time } \\
ID & PMCH & mcPDCH & (hours) \\
2682 & 0.24 & 0.37 & 2 \\
4322 & 0.15 & 0.23 & 4 \\
3192 & 0.11 & 0.15 & 6 \\
8176 & 0.08 & 0.08 & 8 \\
8643 & 0.10 & 0.10 & 10 \\
8847 & 0.12 & 0.18 & 12 \\
3708 & 0.10 & 0.10 & 14 \\
4966 & 0.09 & 0.08 & 16 \\
2288 & 0.07 & 0.09 & 18 \\
9770 & 0.10 & 0.16 & 20 \\
1864 & 0.00 & 0.17 & 22 \\
1856 & 0.17 & 0.13 & 24
\end{tabular}


Control Building Elevation 2073 (Upper Cable Spreading Room)

\begin{tabular}{|c|c|c|c|}
\hline \multirow{2}{*}{$\begin{array}{c}\text { Sample } \\
\text { ID }\end{array}$} & \multicolumn{2}{|c|}{ Fractional Depletion } & \multirow{2}{*}{$\begin{array}{l}\text { Stop } \\
\text { (hour }\end{array}$} \\
\hline & $\mathrm{PMCH}$ & $\mathrm{mcPDCH}$ & \\
\hline \multicolumn{3}{|c|}{ BATS 2 UCSR Location 32} & \\
\hline 10885 & 0.29 & 0.43 & 2 \\
\hline 11074 & 0.17 & 0.29 & 4 \\
\hline 11180 & 0.11 & 0.19 & 6 \\
\hline 251 & 0.09 & 0.06 & 8 \\
\hline 2240 & 0.15 & 0.14 & 10 \\
\hline 10224 & 0.10 & 0.07 & 12 \\
\hline 10547 & 0.16 & 0.11 & 14 \\
\hline 10075 & 0.06 & 0.12 & 16 \\
\hline 11434 & 0.13 & 0.10 & 18 \\
\hline 4907 & 0.05 & 0.09 & 20 \\
\hline 11830 & 0.10 & 0.15 & 22 \\
\hline 1434 & 0.06 & 0.12 & 24 \\
\hline
\end{tabular}

\begin{tabular}{cccc}
$\begin{array}{c}\text { Sample } \\
\text { ID }\end{array}$ & \multicolumn{2}{c}{$\begin{array}{c}\text { Fractional Depletion } \\
\text { PMCH }\end{array}$} & $\begin{array}{c}\text { Stop Time } \\
\text { (hours) }\end{array}$ \\
8088 & $\begin{array}{c}\text { BATS 11 EL } \\
\text { 2073 (UCSR) Loc 33 }\end{array}$ \\
9876 & 0.26 & 0.47 & 2 \\
11289 & 0.15 & 0.36 & 4 \\
2763 & 0.11 & 0.21 & 6 \\
8180 & 0.08 & 0.16 & 8 \\
2196 & 0.00 & 0.00 & 10 \\
10836 & 0.13 & 0.24 & 12 \\
12425 & 0.15 & 0.21 & 14 \\
4152 & 0.09 & 0.17 & 16 \\
11117 & 0.10 & 0.16 & 18 \\
10620 & 0.12 & 0.18 & 20 \\
1373 & 0.09 & 0.15 & 22 \\
& 0.10 & 0.22 & 24
\end{tabular}

\begin{tabular}{cccc}
$\begin{array}{c}\text { Sample } \\
\text { ID }\end{array}$ & Fractional Depletion & $\begin{array}{c}\text { Stop Time } \\
\text { (hours) }\end{array}$ \\
\multicolumn{5}{c}{ PMCH } & mcPDCH & BATS 36 EL 2073 (UCSR) Loc 34 \\
6925 & 0.26 & 0.41 & 2
\end{tabular}




$\begin{array}{cccc}6529 & 0.25 & 0.25 & 4 \\ 3512 & 0.13 & 0.19 & 6 \\ 3059 & 0.12 & 0.16 & 8 \\ 2845 & 0.11 & 0.16 & 10 \\ 3029 & 0.12 & 0.21 & 12 \\ 3141 & 0.12 & 0.19 & 14 \\ 3489 & 0.13 & 0.19 & 16 \\ 2712 & 0.10 & 0.15 & 18 \\ 2905 & 0.11 & 0.16 & 20 \\ 2904 & 0.11 & 0.13 & 22 \\ 4346 & 0.17 & 0.12 & 24\end{array}$

\begin{tabular}{|c|c|c|c|}
\hline \multirow{2}{*}{$\begin{array}{c}\text { Sample } \\
\text { ID }\end{array}$} & \multicolumn{2}{|c|}{ Fractional Depletion } & \multirow{2}{*}{$\begin{array}{l}\text { Stop Time } \\
\text { (hours) }\end{array}$} \\
\hline & $\mathrm{PMCH}$ & $\mathrm{mcPDCH}$ & \\
\hline & \multicolumn{3}{|c|}{ BATS 18 EL 2073 (UCSR) Loc 35} \\
\hline 10227 & 0.00 & 0.00 & 2 \\
\hline 10633 & 0.26 & 0.58 & 4 \\
\hline 10940 & 0.23 & 0.34 & 6 \\
\hline 11140 & 0.23 & 0.17 & 8 \\
\hline 11481 & 0.10 & 0.23 & 10 \\
\hline 10239 & 0.13 & 0.20 & 12 \\
\hline 10086 & 0.13 & 0.23 & 14 \\
\hline 11073 & 0.18 & 0.18 & 16 \\
\hline 4596 & 0.18 & 0.20 & 18 \\
\hline 4000 & 0.10 & 0.16 & 20 \\
\hline 11933 & 0.10 & 0.15 & 22 \\
\hline 11751 & 0.12 & 0.17 & 24 \\
\hline
\end{tabular}




\section{Control Room}

BATS

54

MCR RA 2

Sample

ID

$\mathrm{mtPDCH}$

12449

12092

11032

1118

6558

12210

10460

10977

11722

11164

pcPDCH mcPDCH ptPDCH Hours

pcPDCH mcPDCH ptPDCH Hours

$\begin{array}{lllll}0.046 & 0.085 & 0.048 & 0.034 & 2\end{array}$

$\begin{array}{lllll}0.034 & 0.066 & 0.039 & 0.018 & 4\end{array}$

$\begin{array}{lllll}0.031 & 0.054 & 0.034 & 0.017 & 6\end{array}$

$\begin{array}{lllll}0.029 & 0.061 & 0.030 & 0.017 & 8\end{array}$

$\begin{array}{lllll}0.027 & 0.045 & 0.030 & 0.016 & 10\end{array}$

$\begin{array}{lllll}0.030 & 0.046 & 0.032 & 0.017 & 12\end{array}$

$\begin{array}{lllll}0.027 & 0.046 & 0.028 & 0.016 & 14\end{array}$

$\begin{array}{lllll}0.026 & 0.048 & 0.028 & 0.016 & 16\end{array}$

$\begin{array}{lllll}0.024 & 0.047 & 0.025 & 0.013 & 20\end{array}$

$\begin{array}{lllll}0.024 & 0.045 & 0.026 & 0.015 & 24\end{array}$

BATS

47 MCR 2nd Hall

Sample

ID

9418
10468
11997
10117
11066
2375

$\mathrm{mtPDCH}$

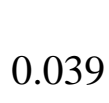

0.027

0.024

0.021

0.023

0.023
pcPDCH mcPDCH

0.075

0.044

0.043

0.043

0.041

0.051

0.048

\begin{tabular}{rrr} 
ptPDCH & ptPCH & \multicolumn{1}{l}{ Hours } \\
0.041 & 0.050 & 4 \\
0.029 & 0.029 & 8 \\
0.027 & 0.019 & 12 \\
0.023 & 0.021 & 16 \\
0.026 & 0.020 & 20 \\
0.025 & 0.026 & 24
\end{tabular}

Stop

Time

4 8

16

24

\section{BATS}

48 MCR 1st Hall

Sample

ID

$\mathrm{mtPDCH}$

11862

533

3603

3169

2088

7380

Stop

Time

pcPDCH mcPDCH ptPDCH Hours

$\begin{array}{llllr}0.058 & 0.061 & 0.070 & 0.032 & 4 \\ 0.045 & 0.029 & 0.010 & 0.030 & 8 \\ 0.034 & 0.025 & 0.011 & 0.025 & 12 \\ 0.035 & 0.026 & 0.038 & 0.028 & 16 \\ 0.036 & 0.025 & 0.038 & 0.025 & 20 \\ 0.014 & 0.012 & 0.018 & 0.011 & 24\end{array}$


Auxiliary Building

Inactive Equipment Room

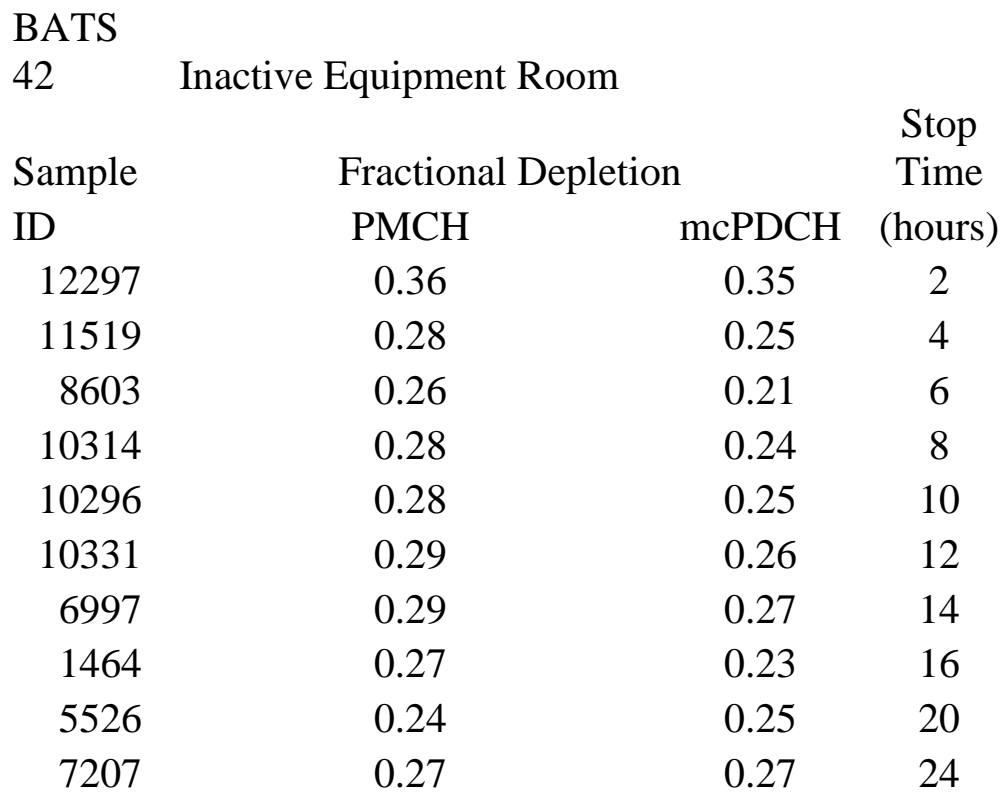

Active Equipment Room

BATS

28 Aux Near CREVS

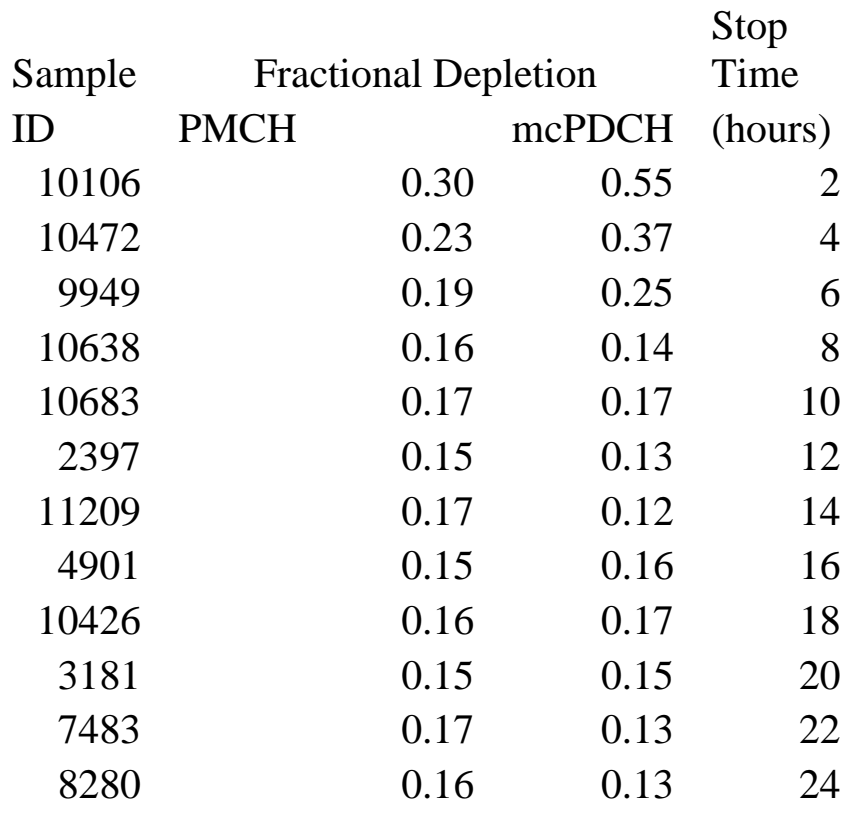


BATS

39

Below Supply Air Duct

Sample

ID

11785

10207

12151

8470

6078

11402

4455

10617

11124

908

Fractional Depletion $\mathrm{mtPDCH}$

0.000

0.295

0.160

0.113

0.099

0.098

0.091

0.092

0.094

0.075

pcPDCH mcPDCH ptPDCH

Stop

Time

$\begin{array}{llll}0.256 & 0.405 & 0.288 & 4\end{array}$

$\begin{array}{llll}0.146 & 0.197 & 0.152 & 6\end{array}$

$\begin{array}{llll}0.094 & 0.144 & 0.103 & 8\end{array}$

$\begin{array}{llll}0.080 & 0.118 & 0.088 & 10\end{array}$

$\begin{array}{llll}0.079 & 0.123 & 0.093 & 12\end{array}$

$\begin{array}{llll}0.083 & 0.112 & 0.087 & 14\end{array}$

$\begin{array}{llll}0.089 & 0.115 & 0.086 & 16\end{array}$

$\begin{array}{llll}0.076 & 0.120 & 0.079 & 20\end{array}$

$\begin{array}{llll}0.068 & 0.099 & 0.071 & 24\end{array}$

\section{CREVS Data}

BATS

93 CREVS Inlet before HEPA

\begin{tabular}{|c|c|c|c|c|c|}
\hline $\begin{array}{l}\text { Sample } \\
\text { ID }\end{array}$ & $\begin{array}{c}\text { Fractional Depletion } \\
\text { mtPDCH }\end{array}$ & $\mathrm{pcPDCH}$ & $\mathrm{mcPDCH}$ & ptPDCH & $\begin{array}{l}\text { Stop } \\
\text { Time } \\
\text { Hours }\end{array}$ \\
\hline 10034 & 0.057 & 0.159 & 0.071 & 0.068 & 4 \\
\hline 4572 & 0.045 & 0.110 & 0.056 & 0.038 & 9 \\
\hline 9734 & 0.046 & 0.103 & 0.056 & 0.063 & 14 \\
\hline 10385 & 0.043 & 0.103 & 0.054 & 0.061 & 19 \\
\hline 11474 & 0.041 & 0.097 & 0.048 & 0.029 & 24 \\
\hline
\end{tabular}

BATS

$94 \quad$ CREVS Inlet after HEPA

Sample Fractional Depletion

ID mtPDCH

$12333 \quad 0.053$

4743

0.046

4934

0.045

10136

0.004

11876

0.041

pcPDCH mcPDCH ptPDCH Hours

$\begin{array}{cccc}0.138 & 0.065 & 0.055 & 4 \\ 0.099 & 0.058 & 0.069 & 9 \\ 0.098 & 0.057 & 0.065 & 14 \\ 0.016 & 0.010 & 0.007 & 19 \\ 0.087 & 0.049 & 0.043 & 24\end{array}$




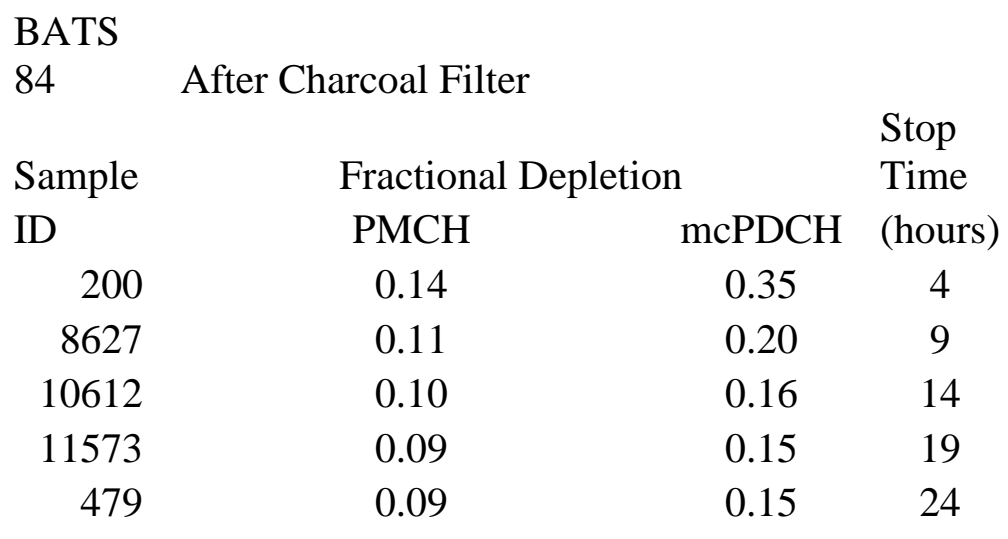

\section{BATS}

91 Crevs Outlet After HEPA 


\section{Bravo Test}

Control Building 2000-foot Elevation (Switchgear Rooms)

Bats 20 EL 2000 SWGR 1-2 Loc 4.

\begin{tabular}{rlrrrr} 
Sample & Fractional Depletion & & & & \multicolumn{2}{l}{$\begin{array}{l}\text { Stop } \\
\text { ID }\end{array}$} & mime \\
1478 & & pcPDCH & mcPDCH & ptPDCH & \multicolumn{1}{l}{ Hours } \\
8955 & 0.169 & 0.254 & 0.191 & 0.358 & 2 \\
9991 & 0.095 & 0.171 & 0.111 & 0.144 & 4 \\
10645 & 0.080 & 0.153 & 0.092 & 0.139 & 6 \\
6001 & 0.070 & 0.164 & 0.082 & 0.120 & 8 \\
10175 & 0.026 & 0.079 & 0.043 & 0.069 & 10 \\
10182 & 0.112 & 0.207 & 0.128 & 0.197 & 12 \\
10040 & 0.098 & 0.159 & 0.111 & 0.197 & 14 \\
11446 & 0.103 & 0.177 & 0.124 & 0.164 & 16 \\
12248 & 0.099 & 0.136 & 0.112 & 0.171 & 18 \\
7730 & 0.097 & 0.178 & 0.118 & 0.161 & 20 \\
1949 & 0.100 & 0.174 & 0.108 & 0.153 & 22 \\
& 0.077 & 0.113 & 0.082 & 0.123 & 24
\end{tabular}

BATS 17 EL 2000 Active RA grill

\begin{tabular}{rlrrrr} 
Sample & Fractional Depletion & & & & \multicolumn{2}{l}{$\begin{array}{l}\text { Stop } \\
\text { ID }\end{array}$} & & & & Time \\
1332 & & pcPDCH & mcPDCH & ptPDCH & Hours \\
638 & 0.317 & 0.479 & 0.232 & 0.165 & 2 \\
8143 & 0.215 & 0.325 & 0.165 & 0.093 & 4 \\
8814 & 0.157 & 0.250 & 0.114 & 0.120 & 6 \\
4398 & 0.153 & 0.243 & 0.112 & 0.107 & 8 \\
1536 & 0.204 & 0.334 & 0.149 & 0.086 & 10 \\
4970 & 0.308 & 0.593 & 0.213 & 0.128 & 12 \\
6365 & 0.270 & 0.530 & 0.197 & 0.133 & 14 \\
608 & 0.308 & 0.622 & 0.221 & 0.146 & 16 \\
8619 & 0.350 & 0.749 & 0.232 & 0.148 & 18 \\
10872 & 0.366 & 0.817 & 0.253 & 0.145 & 20 \\
12216 & 0.385 & 0.878 & 0.262 & 0.158 & 22 \\
& 0.253 & 0.537 & 0.203 & 0.144 & 24
\end{tabular}

BATS 32 EL 2000 beneath Active RA

\begin{tabular}{|c|c|c|c|c|c|c|}
\hline Sample & Fractional Depletion & & & & & $\begin{array}{l}\text { Stop } \\
\text { Time }\end{array}$ \\
\hline ID & $\mathrm{mtPDCH}$ & & pcPDCH & $\mathrm{mcPDCH}$ & ptPDCH & Hours \\
\hline 9805 & & 0.277 & 0.362 & 0.250 & 0.234 & 2 \\
\hline
\end{tabular}




$\begin{array}{rrrrrr}1419 & 0.189 & 0.285 & 0.165 & 0.143 & 4 \\ 7678 & 0.158 & 0.265 & 0.128 & 0.152 & 6 \\ 6321 & 0.175 & 0.288 & 0.154 & 0.137 & 8 \\ 2230 & 0.247 & 0.401 & 0.215 & 0.205 & 10 \\ 7523 & 0.276 & 0.521 & 0.236 & 0.204 & 12 \\ 799 & 0.301 & 0.631 & 0.252 & 0.212 & 14 \\ 3467 & 0.303 & 0.718 & 0.244 & 0.175 & 16 \\ 1681 & 0.287 & 0.741 & 0.188 & 0.157 & 18 \\ 3065 & 0.764 & 2.190 & 0.581 & 0.273 & 20 \\ 5721 & 0.352 & 0.932 & 0.274 & 0.175 & 22 \\ 6457 & 0.231 & 0.520 & 0.185 & 0.192 & 24\end{array}$

BATS 3 EL 2000 Inactive RA

\begin{tabular}{rlrrrr} 
Sample & Fractional Depletion & & & & \multicolumn{2}{c}{ Stop } \\
ID & mtPDCH & & & \multicolumn{2}{c}{ Time } \\
11155 & 0.270 & 0.270 & 0.304 & 0.281 & 2 \\
7201 & 0.153 & 0.150 & 0.185 & 0.139 & 4 \\
3316 & 0.119 & 0.117 & 0.144 & 0.110 & 6 \\
12392 & 0.116 & 0.114 & 0.142 & 0.127 & 8 \\
10632 & 0.152 & 0.156 & 0.195 & 0.141 & 10 \\
3867 & 0.175 & 0.174 & 0.200 & 0.164 & 12 \\
4254 & 0.173 & 0.162 & 0.232 & 0.153 & 14 \\
8003 & 0.164 & 0.164 & 0.187 & 0.156 & 16 \\
2839 & 0.163 & 0.158 & 0.198 & 0.148 & 18 \\
11687 & 0.163 & 0.160 & 0.198 & 0.169 & 20 \\
10202 & 0.151 & 0.154 & 0.178 & 0.135 & 22 \\
11608 & 0.138 & 0.141 & 0.167 & 0.138 & 24
\end{tabular}

BATS 25 EL 2000 SWGR 2-2

Sample Fractional Depletion ID $\mathrm{mtPDCH}$

6647

5244

1608

2164

1636

1771

9179

4214

10805

0.138

0.141

0.167

0.138

24 


$\begin{array}{rlllll}6536 & 0.137 & 0.131 & 0.161 & 0.122 & 20 \\ 9854 & 0.124 & 0.128 & 0.154 & 0.108 & 22 \\ 12214 & 0.117 & 0.117 & 0.154 & 0.141 & 24\end{array}$

BATS 4 EL 2000 SWGR 1-1

\begin{tabular}{|c|c|c|c|c|c|c|}
\hline $\begin{array}{l}\text { Sample } \\
\text { ID }\end{array}$ & $\begin{array}{l}\text { Fractional Depletion } \\
\text { mtPDCH }\end{array}$ & & pcPDCH & $\mathrm{mcPDCH}$ & ptPDCH & $\begin{array}{l}\text { Stop } \\
\text { Time } \\
\text { Hours }\end{array}$ \\
\hline 8073 & & 0.282 & 0.284 & 0.277 & 0.277 & 2 \\
\hline 9187 & & 0.082 & 0.082 & 0.089 & 0.081 & 4 \\
\hline 9039 & & 0.122 & 0.119 & 0.125 & 0.144 & 6 \\
\hline 9518 & & 0.075 & 0.072 & 0.078 & 0.079 & 8 \\
\hline 8264 & & 0.150 & 0.148 & 0.156 & 0.151 & 10 \\
\hline 651 & & 0.177 & 0.175 & 0.175 & 0.179 & 12 \\
\hline 691 & & 0.174 & 0.167 & 0.171 & 0.189 & 14 \\
\hline 8362 & & 0.169 & 0.154 & 0.164 & 0.176 & 16 \\
\hline 7150 & & 0.166 & 0.162 & 0.163 & 0.184 & 18 \\
\hline 916 & & 0.154 & 0.151 & 0.166 & 0.169 & 20 \\
\hline 5472 & & 0.137 & 0.131 & 0.137 & 0.144 & 22 \\
\hline 2940 & & 0.133 & 0.135 & 0.138 & 0.134 & 24 \\
\hline
\end{tabular}


Control Building 2016 Elevation

Bats 45 EL2016 After Charcoal Filter

\begin{tabular}{crrrrr} 
Sample & $\begin{array}{c}\text { Fractional } \\
\text { Depletion }\end{array}$ & & & \multicolumn{2}{c}{$\begin{array}{l}\text { Ttop } \\
\text { Time }\end{array}$} \\
ID & mtPDCH & pcPDCH & mcPDCH & ptPDCH & Hours \\
563 & 0 & 0 & 0 & 0 & 4 \\
938 & 0.180 & 0.196 & 0.181 & 0.112 & 8 \\
3758 & 0.152 & 0.165 & 0.148 & 0.166 & 12 \\
2022 & 0.161 & 0.175 & 0.156 & 0.208 & 16 \\
5783 & 0.176 & 0.193 & 0.184 & 0.229 & 20 \\
7798 & 0.148 & 0.162 & 0.143 & 0.141 & 24
\end{tabular}

Bats 49 EL2016 after charcoal and HEPA filter

\begin{tabular}{lrrrrr}
\multicolumn{1}{c}{ Sample } & $\begin{array}{c}\text { Fractional } \\
\text { Depletion } \\
\text { mtPDCH }\end{array}$ & & & \multicolumn{2}{c}{$\begin{array}{c}\text { Stop } \\
\text { pcPDCH }\end{array}$} \\
ID & 0.000 & 0.000 & 0.000 & 0 & 4 \\
11843 & 0.053 & 0.104 & 0.054 & 0 & 8 \\
11598 & 0.068 & 0.107 & 0.075 & 0.06539 & 12 \\
11595 & 0.079 & 0.097 & 0.079 & 0.00171 & 16 \\
10309 & 0.065 & 0.080 & 0.064 & 0.05554 & 20 \\
8575 & 0.054 & 0.071 & 0.056 & 0.04214 & 24 \\
10214 & & & & & Time
\end{tabular}

Bats 122016 SA Grill

\begin{tabular}{crrrrr} 
Sample & \multicolumn{2}{c}{$\begin{array}{c}\text { Fractional } \\
\text { Depletion }\end{array}$} & & & \multicolumn{2}{c}{ Ttop } \\
ID & mime & & & \multicolumn{1}{l}{ mours } \\
1537 & 0.27 & 0.28 & 0.24 & 0.22 & 2 \\
3805 & 0.17 & 0.20 & 0.14 & 0.14 & 4 \\
2865 & 0.13 & 0.16 & 0.12 & 0.17 & 6 \\
438 & 0.12 & 0.14 & 0.11 & 0.16 & 8 \\
8931 & 0.00 & 0.00 & 0.00 & 0.00 & 10 \\
1895 & 0.19 & 0.35 & 0.18 & 0.25 & 12 \\
5218 & 0.17 & 0.17 & 0.16 & 0.22 & 14 \\
5068 & 0.17 & 0.16 & 0.15 & 0.24 & 16 \\
2937 & 0.19 & 0.20 & 0.17 & 0.27 & 18 \\
12324 & 0.16 & 0.18 & 0.15 & 0.22 & 20 \\
10027 & 0.15 & 0.17 & 0.13 & 0.19 & 22 \\
11418 & 0.13 & 0.14 & 0.12 & 0.18 & 24
\end{tabular}

Bats 16 El 2016 SWBD 1

Sample

Fractional

Stop

Depletion

Time 


ID
8813
11011
931
7062
3738
1274
1496
8295
2059
1960
4453
6436

mtPDCH pcPDCH mcPDCH ptPDCH Hours

$\begin{array}{rrrrr}0.26 & 0.32 & 0.23 & 0.24 & 2 \\ 0.14 & 0.15 & 0.12 & 0.00 & 4 \\ 0.13 & 0.14 & 0.11 & 0.12 & 6 \\ 0.09 & 0.27 & 0.12 & 0.10 & 8 \\ 0.14 & 0.20 & 0.14 & 0.02 & 10 \\ 0.16 & 0.19 & 0.15 & 0.22 & 12 \\ 0.16 & 0.19 & 0.15 & 0.05 & 14 \\ 0.10 & 0.16 & 0.12 & 0.15 & 16 \\ 0.10 & 0.17 & 0.12 & 0.17 & 18 \\ 0.10 & 0.16 & 0.11 & 0.18 & 20 \\ 0.09 & 0.17 & 0.11 & 0.14 & 22 \\ 0.09 & 0.13 & 0.10 & 0.15 & 24\end{array}$

BATs 27 EL 2016 SWBD 2

Sample
ID
6855
11097
10920
11057
12395
12454
10819
11924
10564
10931
6712
991

BATS 44 EL 2016 CBEVS Recirc

Sample
ID
2825
2579
9676
976
11021

Fractional

Depletion

Stop

mtPDCH pcPDCH mcPDCH ptPDCH Hours

Fractional

Stop

Depletion

Time

$\begin{array}{lllll}0.25 & 0.24 & 0.23 & 0.23 & 2\end{array}$

0.16

0.15

0.15

0.16

0.13

0.12

0.12

0.12

0.11

0.11

0.10

0.13

0.08

0.08

0.18

0.07

0.17

0.21

0.06

0.07

0.16

0.15

0.16

0.16

0.18

0.15

0.18

0.14

0.16

0.14

0.14

2
4

6

8

10

12

14

16

0.16

0.16

0.14

0.14

0.14

18

20

22

24


BATS 35 EL 2016 SWBD 4

Sample
ID
11669
590
1481
4769
10119
10736
10996
10462
10741
10621
12495
2128

Fractional

Stop

Depletion Time mtPDCH pcPDCH mcPDCH ptPDCH Hours $\begin{array}{lllll}0.24 & 0.23 & 0.23 & 0.23 & 2\end{array}$

$\begin{array}{lllll}0.14 & 0.13 & 0.13 & 0.13 & 4\end{array}$

$\begin{array}{lllll}0.11 & 0.11 & 0.10 & 0.10 & 6\end{array}$

$\begin{array}{lllll}0.12 & 0.12 & 0.12 & 0.11 & 8\end{array}$

$\begin{array}{lllll}0.42 & 0.16 & 0.91 & 0.17 & 10\end{array}$

$\begin{array}{lllll}0.19 & 0.18 & 0.19 & 0.18 & 12\end{array}$

$\begin{array}{lllll}0.17 & 0.16 & 0.15 & 0.15 & 14\end{array}$

$\begin{array}{lllll}0.16 & 0.16 & 0.15 & 0.14 & 16\end{array}$

$\begin{array}{lllll}0.15 & 0.16 & 0.15 & 0.16 & 18\end{array}$

$\begin{array}{lllll}0.18 & 0.18 & 0.16 & 0.14 & 20\end{array}$

$\begin{array}{lllll}0.14 & 0.13 & 0.13 & 0.12 & 22\end{array}$

$\begin{array}{lllll}0.12 & 0.12 & 0.12 & 0.11 & 24\end{array}$


Control Building 2036-foot Elevation (Lower Cable Spreading Room)

Bats 5 LCSR Front

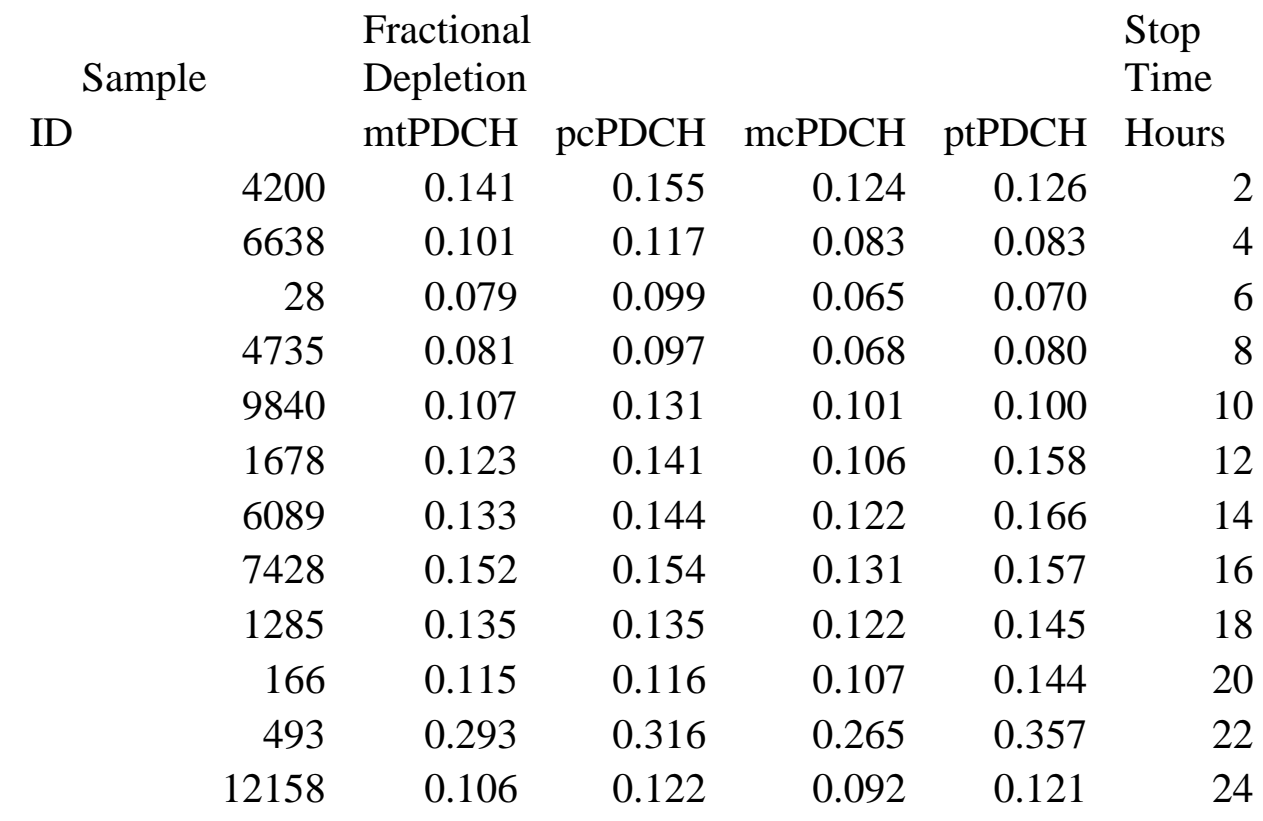

Bats 9 LCSR RA Grill

\begin{tabular}{|c|c|c|c|c|c|}
\hline Sample & $\begin{array}{l}\text { Fractional } \\
\text { Depletion }\end{array}$ & & & & $\begin{array}{l}\text { Stop } \\
\text { Time }\end{array}$ \\
\hline ID & $\mathrm{mtPDCH}$ & pcPDCH & $\mathrm{mcPDCH}$ & $\mathrm{ptPDCH}$ & Hours \\
\hline 2494 & 0.109 & 0.194 & 0.111 & 0.122 & 2 \\
\hline 4795 & 0.061 & 0.138 & 0.066 & 0.005 & 4 \\
\hline 632 & 0.065 & 0.103 & 0.058 & 0.062 & 6 \\
\hline 2742 & 0.063 & 0.111 & 0.051 & 0.054 & 8 \\
\hline 7770 & 0.099 & 0.149 & 0.093 & 0.000 & 10 \\
\hline 7502 & 0.113 & 0.170 & 0.107 & 0.112 & 12 \\
\hline 9403 & 0.101 & 0.156 & 0.097 & 0.089 & 14 \\
\hline 12348 & 0.107 & 0.149 & 0.105 & 0.087 & 16 \\
\hline 8916 & 0.111 & 0.191 & 0.104 & 0.090 & 18 \\
\hline 2950 & 0.100 & 0.166 & 0.093 & 0.005 & 20 \\
\hline 7751 & 0.112 & 0.119 & 0.109 & 0.120 & 22 \\
\hline 11850 & 0.081 & 0.119 & 0.079 & 0.074 & 24 \\
\hline
\end{tabular}


BATS 13 LCSR Middle

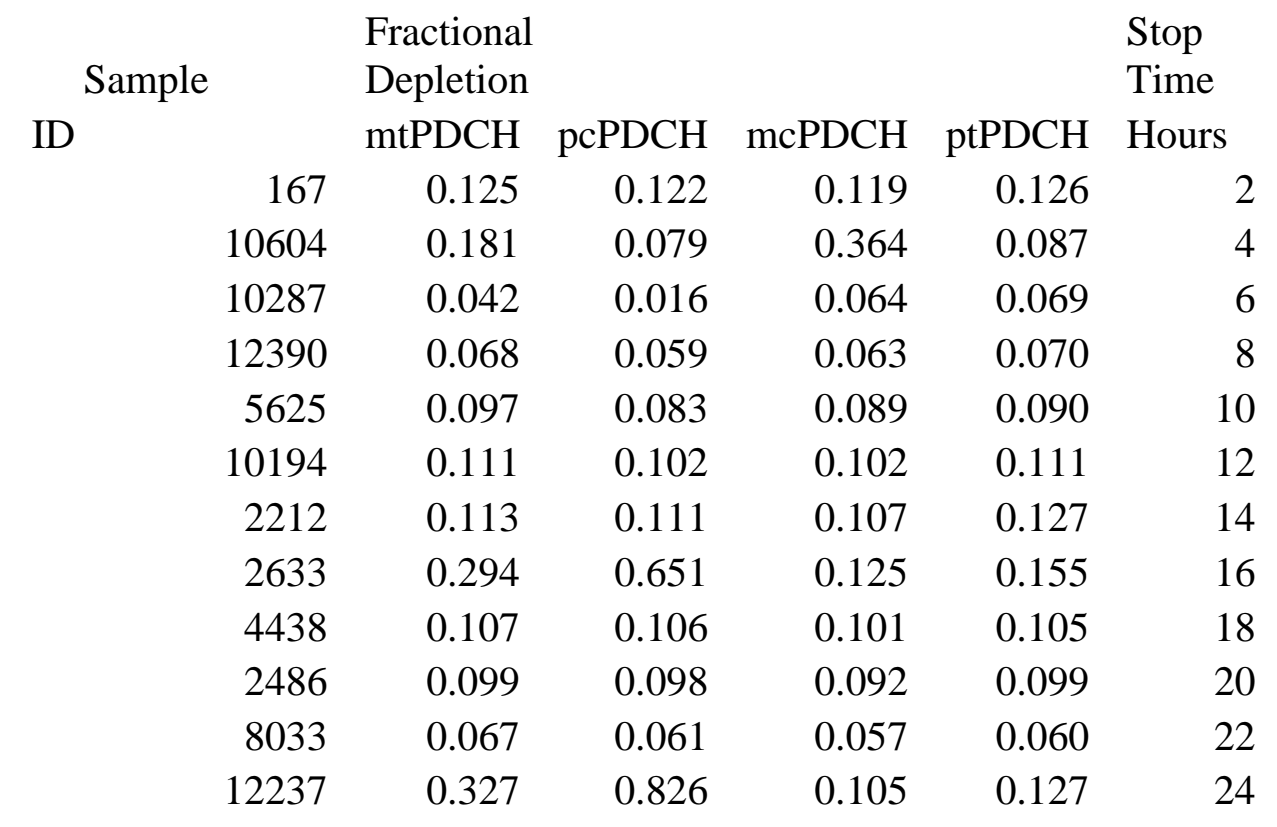

BATS 6 LCSR back

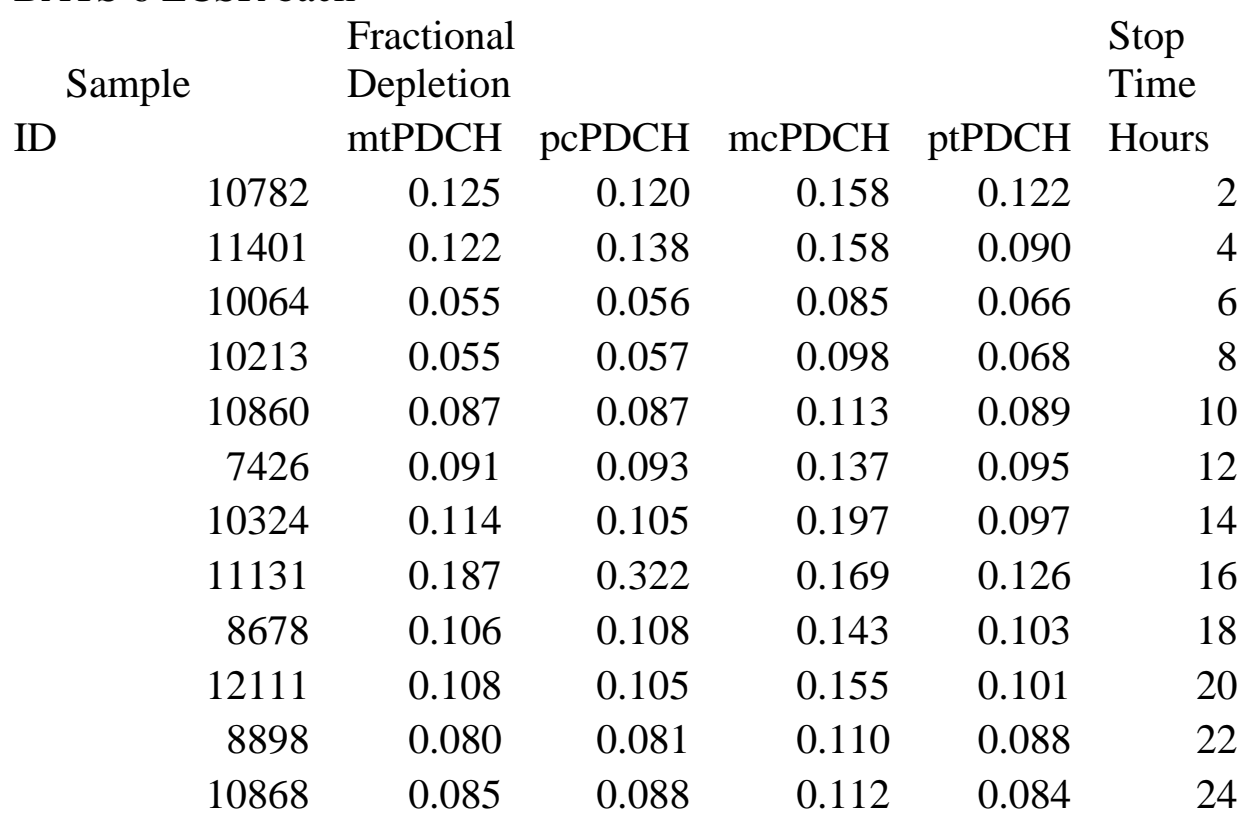


Control Building Elevation 2073 (Upper Cable Spreading Room)

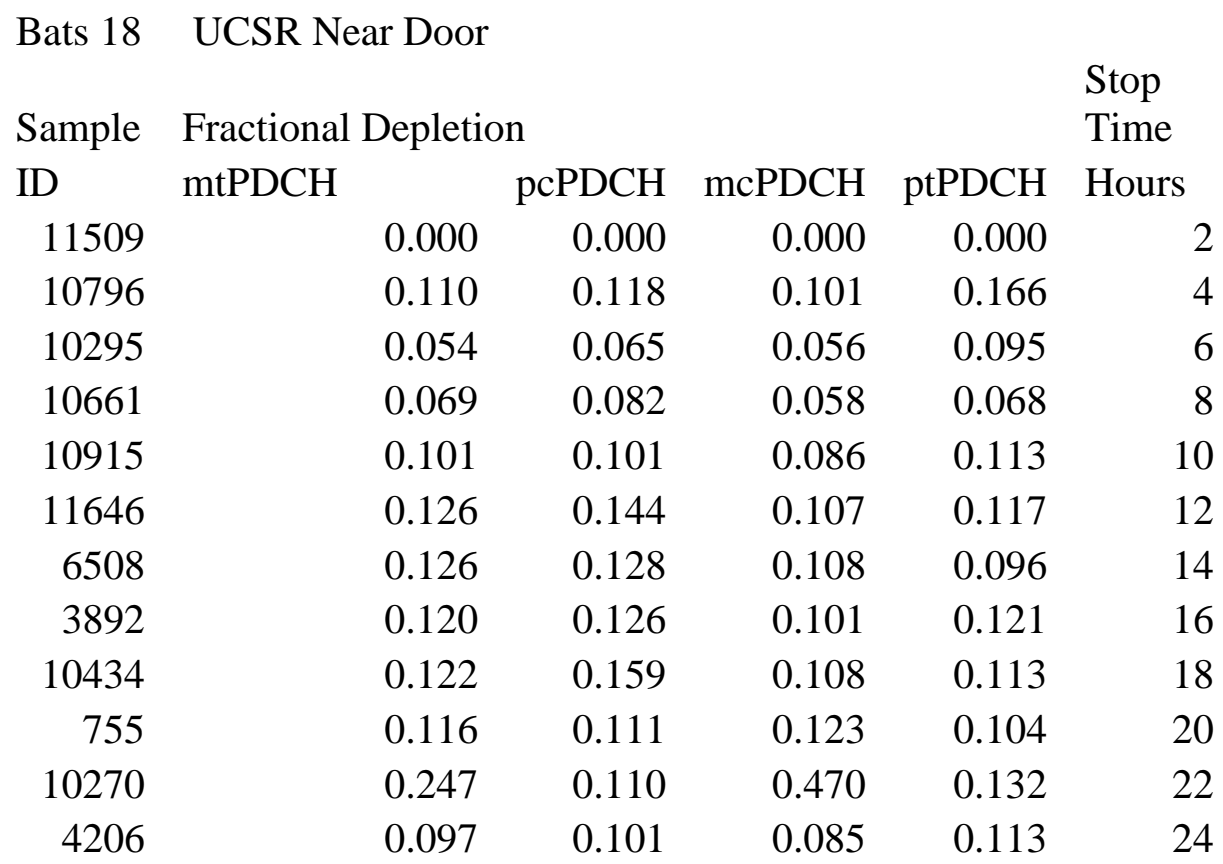

Bats 36 UCSR RA Grill

\begin{tabular}{|c|c|c|c|c|c|}
\hline Sample & Fractional Depletio & & & & $\begin{array}{l}\text { Stop } \\
\text { Time }\end{array}$ \\
\hline ID & $\mathrm{mtPDCH}$ & pcPDCH & $\mathrm{mcPDCH}$ & ptPDCH & Hours \\
\hline 2155 & 0.137 & 0.179 & 0.122 & 0.000 & 4 \\
\hline 2186 & 0.130 & 0.244 & 0.095 & 0.151 & 6 \\
\hline 3183 & 0.074 & 0.100 & 0.058 & 0.062 & 8 \\
\hline 6102 & 0.063 & 0.113 & 0.063 & 0.004 & 10 \\
\hline 3794 & 0.095 & 0.115 & 0.082 & 0.096 & 12 \\
\hline 2622 & 0.153 & 0.260 & 0.125 & 0.042 & 14 \\
\hline 7443 & 0.109 & 0.144 & 0.099 & 0.083 & 16 \\
\hline 6359 & 0.106 & 0.134 & 0.099 & 0.104 & 18 \\
\hline 9835 & 0.100 & 0.135 & 0.095 & 0.010 & 20 \\
\hline 2560 & 0.096 & 0.135 & 0.088 & 0.091 & 22 \\
\hline 8850 & 0.092 & 0.107 & 0.085 & 0.075 & 24 \\
\hline
\end{tabular}

BATS 13 LCSR Middle

Sample Fractional Depletion

ID

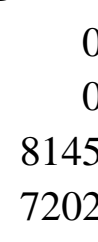
$\mathrm{mtPDCH}$

0

0

7202

0

pcPDCH mcPDCH ptPDCH Hours

$\begin{array}{rrr}0 & 0 & 0\end{array}$

$\begin{array}{llll}0.000 & 0.000 & 0.000 & 0.000\end{array}$

0.130

0.089

0.129

$0.113 \quad 0.125$

$0.088 \quad 0.096$

Stop

Time 


$\begin{array}{rrrrrr}10230 & 0.065 & 0.026 & 0.113 & 0.119 & 6 \\ 8784 & 0.070 & 0.062 & 0.059 & 0.075 & 8 \\ 6343 & 0.090 & 0.077 & 0.084 & 0.086 & 10 \\ 3848 & 0.108 & 0.105 & 0.103 & 0.111 & 12 \\ 3951 & 0.106 & 0.099 & 0.097 & 0.097 & 14 \\ 919 & 0.108 & 0.095 & 0.101 & 0.091 & 16 \\ 1526 & 0.105 & 0.097 & 0.089 & 0.101 & 18 \\ 4056 & 0.091 & 0.083 & 0.084 & 0.093 & 20 \\ 7690 & 0.083 & 0.077 & 0.082 & 0.083 & 22 \\ 1273 & 0.10842 & 0.10989 & 0.08792 & 0.0746 & 24\end{array}$

\begin{tabular}{|c|c|c|c|c|c|}
\hline Sample & Fractional Depletio & & & & $\begin{array}{l}\text { Stop } \\
\text { Time }\end{array}$ \\
\hline ID & $\mathrm{mtPDCH}$ & pcPDCH & $\mathrm{mcPDCH}$ & $\mathrm{ptPDCH}$ & Hours \\
\hline 11915 & 0.127 & 0.142 & 0.132 & 0.145 & \\
\hline 11260 & 0.109 & 0.631 & 0.256 & 0.153 & 4 \\
\hline 10128 & 0.066 & 0.058 & 0.072 & 0.113 & \\
\hline 10543 & 0.368 & 1.062 & 0.272 & 0.179 & 8 \\
\hline 10416 & 0.074 & 0.066 & 0.084 & 0.104 & 10 \\
\hline 10886 & 0.100 & 0.095 & 0.112 & 0.165 & 12 \\
\hline 10445 & 0.076 & 0.077 & 0.109 & 0.121 & 14 \\
\hline 11358 & 0.099 & 0.098 & 0.112 & 0.125 & 16 \\
\hline 10022 & 0.469 & 1.321 & 0.351 & 0.203 & 18 \\
\hline 11357 & 0.117 & 0.181 & 0.114 & 0.111 & 20 \\
\hline 6870 & 0.081 & 0.071 & 0.086 & 0.188 & 22 \\
\hline 8428 & 0.07176 & 0.0691 & 0.08097 & 0.09376 & 24 \\
\hline
\end{tabular}




\section{Control Room}

Bats $40 \quad$ MCR RA Grill 1

$\begin{array}{ccccccc}\text { Sample } & \text { Fractional } & \begin{array}{c}\text { Depletion } \\ \text { pcPDCH }\end{array} & \text { otPDCH } & \text { mcPDCH } & \text { ptPDCH } & \text { Hours } \\ \text { ID } & \text { mtPDCH } & \text { Time } \\ 7752 & 0.030 & 0.046 & 0.006 & 0.027 & 0.001 & 2 \\ 6040 & 0.025 & 0.055 & 0.009 & 0.026 & 0.023 & 4 \\ 9226 & 0.020 & 0.041 & 0.003 & 0.021 & 0.019 & 6 \\ 1376 & 0.023 & 0.039 & 0.002 & 0.019 & 0.007 & 8 \\ 9075 & 0.021 & 0.041 & 0.005 & 0.019 & 0.001 & 10 \\ 9209 & 0.022 & 0.037 & 0.001 & 0.018 & 0.018 & 12 \\ 8268 & 0.019 & 0.034 & 0.003 & 0.019 & 0.008 & 14 \\ 10763 & 0.020 & 0.042 & 0.001 & 0.017 & 0.001 & 16 \\ 7045 & 0.019 & 0.033 & 0.002 & 0.016 & 0.018 & 20 \\ 9736 & 0.019 & 0.036 & 0.001 & 0.017 & 0.002 & 24\end{array}$

\section{BATS}

48

Sample
ID
9653
11280
8523
9878
10357
11029

BATS

47

$\begin{array}{cc}\begin{array}{c}\text { Sample } \\ \text { ID }\end{array} & \begin{array}{c}\text { Fractional } \\ \text { mtPDCH }\end{array} \\ 8913 & 0.029 \\ 4069 & 0.043 \\ 10733 & 0.064 \\ 11445 & 0.080 \\ 10487 & 0.079 \\ 2992 & 0.068\end{array}$

\section{Control Room Hall 2}

Depletion pcPDCH

0.019

$$
0.014
$$$$
0.015
$$$$
0.015
$$$$
0.017
$$$$
0.002
$$

Stop

Time

otPDCH mcPDCH ptPDCH Hours

$\begin{array}{cccc}0.001 & 0.002 & 0.003 & 4 \\ 0.001 & 0.007 & 0.005 & 8 \\ 0.001 & 0.002 & 0.001 & 12 \\ 0.000 & 0.002 & 0.003 & 16 \\ 0.002 & 0.002 & 0.004 & 20 \\ 0.000 & 0.002 & 0.006 & 24\end{array}$

\section{RA Grill 2}

(bad data)

$\begin{array}{ccccc}\begin{array}{c}\text { Depletion } \\ \text { pcPDCH }\end{array} & \text { otPDCH } & \text { mcPDCH } & \text { ptPDCH } & \begin{array}{c}\text { Stop } \\ \text { Time }\end{array} \\ 0.120 & 0.006 & 0.014 & 0.006 & 4 \\ 0.182 & 0.014 & 0.034 & 0.103 & 8 \\ 0.273 & 0.016 & 0.044 & 0.009 & 12 \\ 0.320 & 0.019 & 0.051 & 0.003 & 16 \\ 0.335 & 0.021 & 0.060 & 0.042 & 20 \\ 0.283 & 0.015 & 0.044 & 0.002 & 24\end{array}$


Bats 54

$\begin{array}{ccccccc}\begin{array}{c}\text { Sample } \\ \text { ID }\end{array} & \begin{array}{c}\text { Fractional } \\ \text { mtPDCH }\end{array} & \begin{array}{c}\text { Depletion } \\ \text { pcPDCH }\end{array} & \text { otPDCH } & \text { mcPDCH } & \text { ptPDCH } & \text { Hours } \\ 11054 & 0.043 & 0.110 & 0.006 & 0.017 & 0.133 & 2 \\ 10412 & 0.034 & 0.065 & 0.007 & 0.015 & 0.087 & 4 \\ 10335 & 0.000 & 0.075 & 0.004 & 0.010 & 0.076 & 6 \\ 10960 & 0.000 & 0.068 & 0.004 & 0.010 & 0.059 & 8 \\ 11137 & 0.000 & 0.086 & 0.006 & 0.009 & 0.063 & 10 \\ 10597 & 0.000 & 0.091 & 0.004 & 0.011 & 0.094 & 12 \\ 10511 & 0.000 & 0.154 & 0.007 & 0.013 & 0.109 & 14 \\ 10200 & 0.031 & 0.136 & 0.008 & 0.014 & 0.137 & 16 \\ 10293 & 0.039 & 0.135 & 0.008 & 0.017 & 0.149 & 20 \\ 12016 & 0.033 & 0.143 & 0.009 & 0.017 & 0.148 & 24\end{array}$


$\underline{\text { Auxiliary Building }}$

Inactive Equipment Room

Inactive

BATS Equipment

42 Room

Sample Fractional Depletion Time

ID mtPDCH pcPDCH otPDCH mcPDCH ptPDCH Hours

$\begin{array}{ccccccc}10256 & 0.135 & 0.131 & 0.142 & 0.154 & 0.130 & 2 \\ 4032 & 0.051 & 0.048 & 0.059 & 0.063 & 0.047 & 4 \\ 5013 & 0.076 & 0.073 & 0.085 & 0.091 & 0.075 & 6 \\ 10122 & 0.095 & 0.094 & 0.104 & 0.112 & 0.096 & 8 \\ 3974 & 0.106 & 0.105 & 0.107 & 0.123 & 0.104 & 10 \\ 10865 & 0.113 & 0.112 & 0.109 & 0.130 & 0.112 & 12 \\ 8589 & 0.115 & 0.111 & 0.119 & 0.131 & 0.112 & 14 \\ 11517 & 0.069 & 0.068 & 0.073 & 0.078 & 0.070 & 16 \\ 9699 & 0.083 & 0.081 & 0.092 & 0.098 & 0.081 & 20 \\ 8432 & 0.044 & 0.042 & 0.061 & 0.055 & 0.044 & 24\end{array}$

Active Equipment Room

BATS

39 Below RA Grill

$\begin{array}{ccccccc}\text { Sample } & \text { Fractional } & \begin{array}{c}\text { Depletion } \\ \text { mtPDCH }\end{array} & \begin{array}{c}\text { Stop } \\ \text { ID }\end{array} & \text { mime } \\ 6062 & 0.087 & 0.088 & 0.173 & 0.100 & 0.084 & 2 \\ 11299 & 0.044 & 0.044 & 0.079 & 0.054 & 0.043 & 4 \\ 11309 & 0.027 & 0.024 & 0.068 & 0.044 & 0.024 & 6 \\ 11725 & 0.023 & 0.023 & 0.049 & 0.034 & 0.024 & 8 \\ 10557 & 0.022 & 0.023 & 0.060 & 0.033 & 0.025 & 10 \\ 11486 & 0.024 & 0.022 & 0.051 & 0.034 & 0.021 & 12 \\ 11631 & 0.026 & 0.025 & 0.048 & 0.036 & 0.028 & 14 \\ 11262 & 0.027 & 0.026 & 0.061 & 0.039 & 0.024 & 16 \\ 11713 & 0.030 & 0.028 & 0.046 & 0.039 & 0.032 & 20 \\ 11494 & 0.029 & 0.028 & 0.045 & 0.040 & 0.032 & 24\end{array}$




\begin{tabular}{|c|c|c|c|c|c|c|}
\hline $\begin{array}{c}\text { BATS } \\
28\end{array}$ & $\begin{array}{c}\text { Below Active } \\
\text { Room Near } \\
\text { CREVS }\end{array}$ & & & & & \\
\hline $\begin{array}{c}\text { Sample } \\
\text { ID }\end{array}$ & $\begin{array}{l}\text { Fractional } \\
\mathrm{mtPDCH}\end{array}$ & $\begin{array}{l}\text { Depletion } \\
\text { pcPDCH }\end{array}$ & otPDCH & $\mathrm{mcPDCH}$ & ptPDCH & $\begin{array}{l}\text { Stop } \\
\text { Time } \\
\text { Hours }\end{array}$ \\
\hline & 0 & 0 & 0 & 0 & 0 & 2 \\
\hline 11581 & 0.078 & 0.077 & 0.148 & 0.110 & 0.097 & 4 \\
\hline 12193 & 0.443 & 0.427 & 0.474 & 0.488 & 0.443 & 6 \\
\hline 1278 & 0.438 & 0.436 & 0.497 & 0.499 & 0.478 & 8 \\
\hline 9982 & 0.428 & 0.416 & 0.453 & 0.474 & 0.419 & 10 \\
\hline 2833 & 0.627 & 0.704 & 0.704 & 0.671 & 0.572 & 12 \\
\hline 3499 & 0.510 & 0.498 & 0.503 & 0.556 & 0.508 & 14 \\
\hline 1611 & 0.250 & 0.243 & 0.252 & 0.287 & 0.254 & 16 \\
\hline 1115 & 0.153 & 0.154 & 0.154 & 0.189 & 0.147 & 18 \\
\hline 9816 & 0.104 & 0.104 & 0.152 & 0.139 & 0.123 & 20 \\
\hline 6603 & 0.097 & 0.096 & 0.147 & 0.139 & 0.135 & 22 \\
\hline 2968 & 0.102 & 0.084 & 0.806 & 0.128 & 0.091 & 24 \\
\hline
\end{tabular}

CREVS System

BATS Aux after

84 Charcoal

$\begin{array}{ccccccc}\text { Sample } & \text { Fractional } & \text { Depletion } & & & & \begin{array}{c}\text { Stop } \\ \text { Time }\end{array} \\ \text { ID } & \text { mtPDCH } & \text { pcPDCH } & \text { otPDCH } & \text { mcPDCH } & \text { ptPDCH } & \text { Hours } \\ 1404 & 0.017 & 0.051 & 0.001 & 0.020 & 0.018 & 4 \\ 3761 & 0.010 & 0.032 & 0.001 & 0.010 & 0.000 & 9 \\ 2254 & 0.011 & 0.030 & 0.001 & 0.013 & 0.013 & 14 \\ 1180 & 0.012 & 0.032 & 0.001 & 0.014 & 0.000 & 19 \\ 5497 & 0.015 & 0.036 & 0.001 & 0.018 & 0.016 & 24\end{array}$

\section{CREVS}

outlet

BATS after

91 HEPA

$\begin{array}{ccccccc}\text { Sample } & \text { Fractional } & \text { Depletion } & & & & \text { Stop } \\ \text { ID } & \text { mtPDCH } & \text { pcPDCH } & \text { otPDCH } & \text { mcPDCH } & \text { ptPDCH } & \text { Hours } \\ 10126 & 0.003 & 0.023 & 0.000 & 0.004 & 0.000 & 4 \\ 7175 & 0.003 & 0.015 & 0.000 & 0.003 & 0.004 & 9 \\ 11361 & 0.003 & 0.015 & 0.000 & 0.003 & 0.004 & 14 \\ 9729 & 0.004 & 0.015 & 0.000 & 0.003 & 0.000 & 19 \\ 1120 & 0.000 & 0.085 & 0.004 & 0.010 & 0.004 & 24\end{array}$




\begin{tabular}{|c|c|c|c|c|c|c|}
\hline $\begin{array}{c}\text { BATS } \\
93\end{array}$ & $\begin{array}{c}\text { CREVS } \\
\text { inlet } \\
\text { before } \\
\text { HEPA }\end{array}$ & & & & & \\
\hline & & & & & & Stop \\
\hline Sample & Fractional & Depletion & & & & Time \\
\hline ID & $\mathrm{mtPDCH}$ & pcPDCH & otPDCH & $\mathrm{mcPDCH}$ & ptPDCH & Hours \\
\hline 10788 & 0.024 & 0.023 & 0.000 & 0.025 & 0.024 & 4 \\
\hline 3482 & 0.013 & 0.016 & 0.000 & 0.015 & 0.014 & 8 \\
\hline 7098 & 0.019 & 0.018 & 0.000 & 0.019 & 0.028 & 12 \\
\hline 1612 & 0.010 & 0.012 & 0.000 & 0.012 & 0.020 & 16 \\
\hline 4117 & 0.019 & 0.018 & 0.000 & 0.020 & 0.025 & 20 \\
\hline 378 & 0.027 & 0.037 & 0.000 & 0.026 & 0.026 & 24 \\
\hline
\end{tabular}

\section{CREVS}

BATS inlet after

94 HEPA

ID mtPDCH pcPDCH otPDCH mcPDCH ptPDCH Hours

$\begin{array}{lllllll}11630 & 0.027 & 0.025 & 0.020 & 0.025 & 0.023 & 4 \\ 11547 & 0.017 & 0.015 & 0.011 & 0.015 & 0.014 & 8 \\ 10447 & 0.020 & 0.020 & 0.014 & 0.019 & 0.017 & 12 \\ 11036 & 0.022 & 0.021 & 0.018 & 0.022 & 0.019 & 16 \\ 11527 & 0.022 & 0.019 & 0.016 & 0.021 & 0.018 & 20 \\ 11743 & 0.015 & 0.013 & 0.017 & 0.018 & 0.015 & 24\end{array}$

